\title{
Review on Diffuser Augmented Wind Turbine (DAWT)
}

\section{Balasem Abdulameer Jabbar Al-Quraishi ${ }^{1,2}$, Nor Zelawati Binti Asmuin ${ }^{1}$, Sofian Bin Mohd $^{1}$, Wisam A. Abd al-wahid ${ }^{2}$, Akmal Nizam Mohammed ${ }^{1}$, Djamal Hissein Didane $^{1}$}

${ }^{1}$ Faculty of Mechanical and Manufacturing Engineering, University Tun Hussein Onn Malaysia (UTHM), Parit Raja, Batu Pahat, Johor, MALAYSIA

${ }^{2}$ Engineering Technical College of Al Najaf, Al-Furat Al-Awsat Technical University, Al Najaf, IRAQ.

*Corresponding Author

DOI: https://doi.org/10.30880/ijie.2019.11.01.021

Received 11 June 2018; Accepted 04 September 2018; Available online 30 April 2019

\begin{abstract}
Wind energy technology is one of the fastest growing alternative energy technologies. However, conventional turbines commercially available in some countries are designed to operate at relatively high speeds to be appropriately efficient, limiting the use of wind turbines in areas with low wind speeds, such as urban areas. Therefore, a technique to enhance the possibility of wind energy use within the range of low speeds is needed. The techniques of augmenting wind by the concept of Diffuser Augmented Wind Turbine (DAWT) have been used to improve the efficiency of the wind turbines by increasing the wind speed upstream of the turbine. In this paper, a comprehensive review of previous studies on improving or augmentation power of horizontal axis wind turbines (HAWT) have been reviewed in two categories, first related with relative improvement of energy by improving the aerodynamic forces that affecting on HAWT in some different modifications for blades. Second, reviews different techniques to the augment the largest possible amount of power from HAWT focusing on DAWTs to gather information, helping researchers understand the research efforts undertaken so far and identify knowledge gaps in this area. DAWTs are studied in terms of diffuser shape design, sizing of investigation and geometry features which involved diffuser length, diffuser angle, and flange height. The conclusions in this work show that the use of DAWT achieves a quantum leap in increasing the production of wind power, especially in small turbines in urban areas if it properly designed. On the other hand, shrouding the wind turbine by the diffuser reduces the noise and protects the rotor blades from possible damage.
\end{abstract}

Keywords: Wind Energy, Power Augmentation, DAWT, (Horizontal Axis Wind Turbine) HAWT.

\section{Introduction}

The need for energy in societies increases as technology advances in certain areas, so the capability to produce energy must keep pace with increasing demands. Due to the rapid depletion of fossil energy sources, there is a necessary need to seek alternative and sustainable sources of energy [1]-[10]. As such, wind energy as a renewable and inexhaustible source of energy is now the fastest growing energy technology worldwide. Compared to conventional energy sources, wind power has many advantages and benefits. Unlike fossil fuels that emit harmful gases and nuclear power that generates radioactive wastes, wind power is a clean and environmentally friendly energy source. As an inexhaustible and free energy source, it is available and plentiful in most regions of the earth. In addition, more extensive use of wind power would help reduce the demands for fossil fuels, which may run out sometime in this century, according to present levels of consumption [1],[2],[10]-[12]. As providing of electrical power from renewable sources such as wind is one of the factors of economic growth and industrialization for any nation [8].Wind power systems, represented by wind turbines have been the focus of interest of scientists and researchers in the past decades. Flowing of wind through the turbine rotor leads to produce mechanical energy which can be used in many applications specially to produce

*Corresponding author: balasemalquraishi@etcn.edu.iq ; balasemalquraishi@gmail.com 2019 UTHM Publisher. All right reserved. penerbit.uthm.edu.my/ojs/index.php/ijie 

electricity. However, power produced by wind turbine is dependent on the Betz limit; an ideal type can extract only $59.3 \%$ of incoming energy in stream-tube by turbine blades [14],[15].

The power from wind can be augmented by different innovative concepts have been proposed to augment wind turbine power output including the counter-rotation technique [16],[17]. The question arises as to which of these concepts is the most effective and economical. Performance of wind turbines can be improved by various ways such as modification of blades design, the augmentation attempts by application of tip vanes on the rotor blades, vortex type augmentation devices and ducted wind turbine by shrouds, concentrators or diffusers. Most of the research show that the Diffuser Augmented Wind Turbine (DAWT) exhibits advantages compared to other augmentation solutions [18],[19], where the concept of DAWT is introduced to increase the power by enclosing the turbine with a duct (shroud). Wind power is directly proportional to the cubic of free stream velocity of wind where increasing wind velocity through the rotor plane leads to increase wind turbine power. The technique of augmenting wind turbine results from two fundamental concentrator mechanisms [20],[21], which are the increase mass flux and wake mixing with the external flow, and can be considered from a vorticity point of view [22],[23].

This work aims to give a review of theoretical, simulation and experimental studies done on DAWTs with different configurations and some of the conventional techniques on HAWT. Also, to summarize the important most considered parameters to be easy to achieve the optimum design of DAWT that suitable for the low wind speed areas, especially urban areas. Collecting this information may help researchers understand research efforts by other researchers and identify knowledge gaps in the field. Hence, they may come up with areas of further research until wind energy technologies become suitable contenders of conventional energy technologies.

\section{Wind Turbines}

\subsection{Development of Wind Turbines}

Wind energy is abundant, clean, cheap, and used by mankind for centuries in agriculture for water pumping, crop irrigation and grain grinding [24]. A wind turbine is a rotary machine that extracts energy from the wind. Rotor blade is a key element in a wind turbine generator system to convert wind energy into mechanical energy [5]. Nowadays, wind energy is established as a mainstream form of energy in electrical power generation and has been an increasing trend. According to global wind energy outlook, global cumulative installed wind capacity has increased significantly since the year 2001, and reached 539,581 MW in the year 2017 as shown in Fig.1[25].

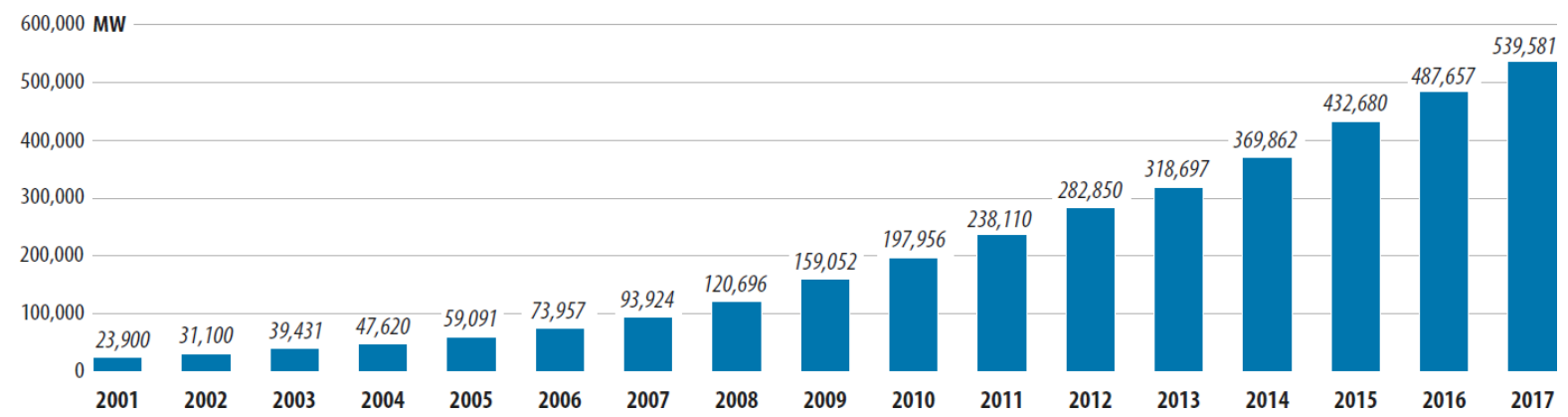

Fig. 1 Global cumulative installed wind capacity from 2001 to 2017 [25].

\subsection{Types of Wind Turbines}

There are various types of wind turbines currently used, they grouped into different classes based on different factors. Wind turbines can be classified as drag and lift types. In drag type turbines, the rotor moves slowly but with high force, so these types of wind turbines are used for irrigation and pumping. Lift type turbines have high rotational speeds, which used for electricity production [12]. Typical classifications include horizontal axis wind turbines (HAWTs) and vertical axis wind turbines (VAWTs), which depend on the orientation of the shaft and rotor axis of rotation ; upwind or downwind turbines, which depend on rotor position in relation to oncoming wind and small or large wind turbines depending on wind turbine power output [2], [26], [27], [28]. The most common design of wind turbines are HAWTs which are generally classified according to the rotor orientation (upwind or downwind of the tower), blade articulation (rigid or teetering), number of blades (generally two or three blades), rotor control (pitch stall) and how they are aligned with wind (free yaw or active yaw). The major components of a HAWT are the rotor, consisting of blades and the supporting hub. The power-train includes the rotating parts of the wind turbine (exclusive of the rotor); it usually consists of shafts, gearbox, coupling, a mechanical brake and generator. The nacelle structure and main frame includes wind turbine housing and yaw system [29]. 


\subsection{Performance Parameters of HAWT}

The performance of HAWT is expressed in dimensionless forms, in terms of power coefficients, $\mathrm{C}_{\mathrm{P}}$ as a function the tip speed ratio, $\lambda$ as shown in Fig. 2 [30]. The basic method for the aerodynamic analysis of wind turbines design employs the Blade Element Momentum (BEM) theory, first proposed by Glauert in 1935 [31]. This method is based on a combination of blade element theory and momentum theory [29],[32].

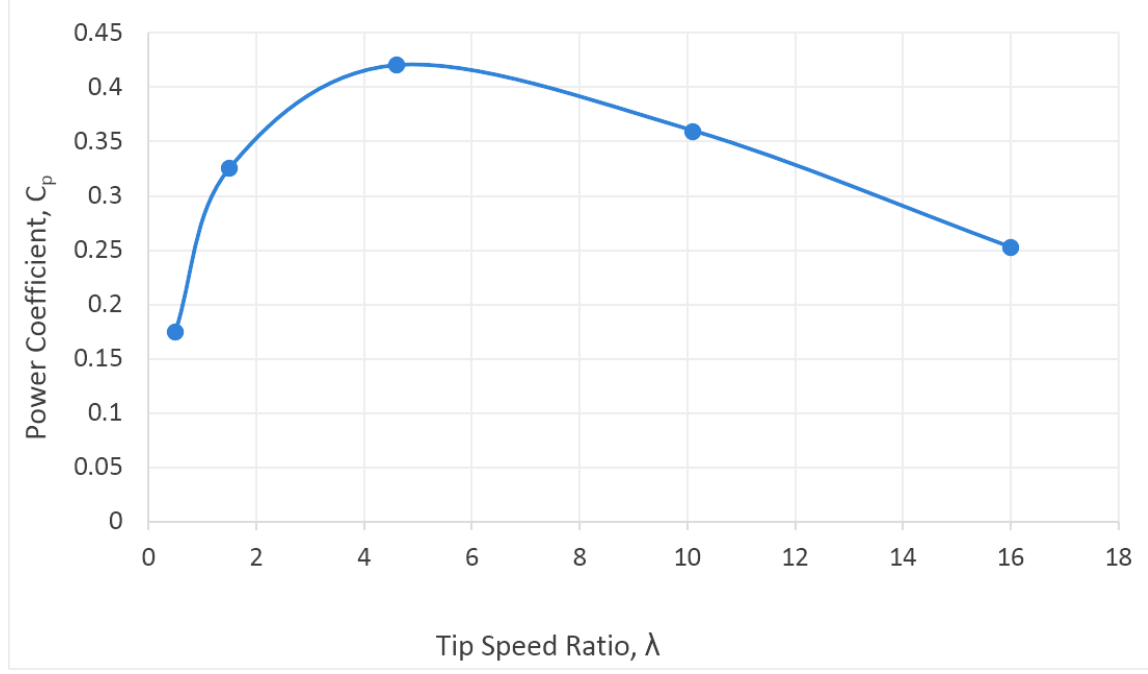

Fig. 2 Typical plot of rotor power coefficient vs. tip-speed ratio for HAWT with a fixed blade pitch angle [30].

\subsection{Background on Performance Improvement of HAWTs}

The conventional technique for improving wind turbine is by improving rotor blade design where the blade is the most important part of a wind turbine. As mentioned in section one, power improvement is achieved by increasing the coefficient of lift or reducing the drag coefficient where lift and drag forces rely mainly on blade geometry and attack angle and the lift force is considered most commonly associated with wind turbines [33]. Many studies have been conducted to increase the efficiency of the horizontal axis wind turbine (HAWT) by improving aerodynamic forces acting on the blade. An example of an optimized model for wind turbine design is the $14 \mathrm{~kW}$ HAWT with three blades designed based on Schmitz law which has developed a little more detailed and sophisticated model of the flow in the rotor plane where it is focused on optimal pitch angle and chord length depending on blade element momentum (BEM) theory. The result showed an increase in coefficient of lift against reducing the coefficient of drag. Hence chord length will be reduced and an optimum pitch angle can be obtained, thus resulting in less forces effecting on the blade and hub [34].

A revised theoretical analysis for the optimal aerodynamics of HAWTs according to BEM theory has been proposed by de Freitas Pinto [35]. The analysis took into account a single airfoil with constant aerodynamics characteristics throughout the whole blade. Tip and hub losses were not considered. It was demonstrated that, in order to reach optimal aerodynamic performance, the ratio between the drag and lift coefficients, for each station, should be the lowest possible. Fig. 3 shows a developed diagram that provides the optimal operating condition and the corresponding maximum power coefficient for each optimum $\mathrm{C}_{\mathrm{D}} / \mathrm{C}_{\mathrm{L}}$.

As computational fluid dynamics (CFD) programs give good predict for flow in 2-Dimensional and 3-Dimensional [36],[37]. A Combination of CFD and BEM methods were used to simulate the flow field around a HAWT rotor. 2D CFD simulation were conducted for airfoil S809 with a 1m chord length (c) and domain size (12 height, 6 upstream, 12 downstream of c). The flow is assumed unsteady and incompressible with SST k- $\omega$ turbulence model was used. The analysis was done at a range of an angle of attack starting from $0^{\circ}$ to $20^{\circ}$ for a of wind speed $14.6 \mathrm{~m} / \mathrm{s}$. The maximum $\mathrm{C}_{\mathrm{L}} / \mathrm{C}_{\mathrm{D}}$ ratio was achieved at $6^{\circ}$ angle of attack. Programming in MATLAB shows that the BEM theory is very successful in HAWT blade design. The modification factor and model were also combined into BEM theory to predict the blade performance and there are good results of torque and thrust in each section between the improved BEM theory and CFD simulation [38]. 


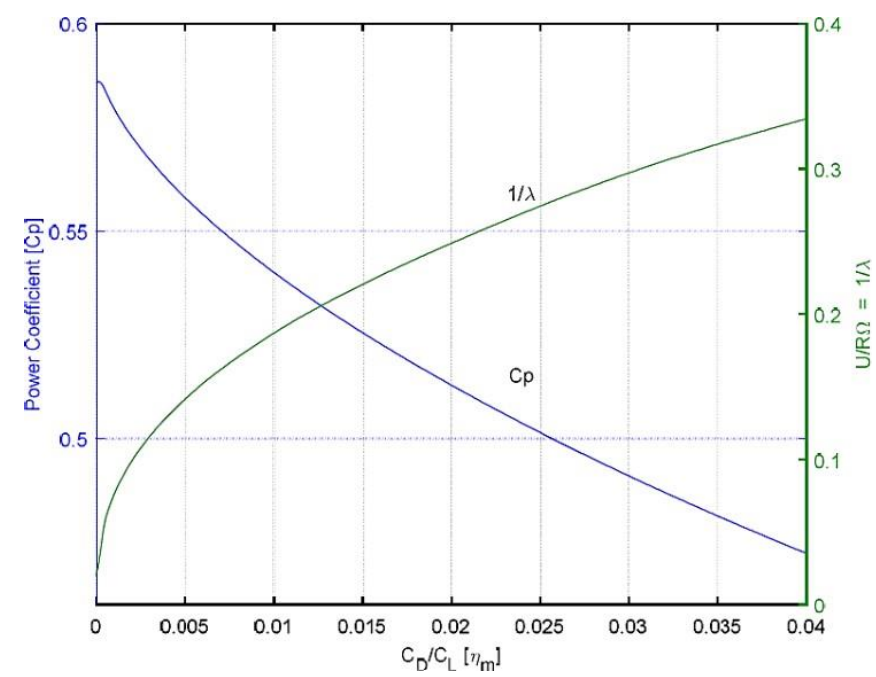

Fig. 3 Optimal values of $1 / \lambda$ and $C_{p}$ as function $C_{D} / C_{L}[35]$.

The efficiency of small HAWT can be increased by slight modification at the tip of blades. Adding a winglet at top of the blade achieves a marked improvement in the performance; the existence of winglet with adequate height and having radius of curvature as low as possible have been found to improve power coefficient. Results of experimental analyses carried out for four different configurations showed maximum power coefficient for small HAWT with effective winglet of up to 0.43 and this will enhance power production to $6 \%$ [39]. From another side, improvement of the power by design of blade at optimum blade angle where the results of CFD analysis for HAWT blade with airfoil NACA 0018 at wind velocity of $32 \mathrm{~m} / \mathrm{s}$ showed the optimum power had been obtained at a pitch angle of $10^{\circ}$ [10].

Experimental tests on a fabricated scaled model of HAWT in wind tunnel has also been conducted atCSIR-SERC, Chennai by K. Sankaranarayanan et al [40], where the model has been designed using Computer Aided Design and Drafting (CADD) based on BEM theory (twisted blade from root to tip). A torque of wind turbine was measured using de Prony brake assembly depending on the product frictional force and radius of the rotor shaft. The rotor torque was measured at a different range of wind speeds $3-9 \mathrm{~m} / \mathrm{s}$ for calculated tip speed ratio. The optimum tip speed-ratio 6 was achieved at wind speeds of $7-8 \mathrm{~m} / \mathrm{s}$. Finally, the increase in wind speed leads to an increase of torque, which means an increase in power. The CFD simulation study showed a favorable feature of the swept-edge blades for smaller turbines where the rotor with swept-edge blade (Fig. 4-b) produced more power up to $10 \%$ more than the rotor with straight-edge (Fig. 4-a) blade at low wind speeds ranging $5-12 \mathrm{~m} / \mathrm{s}$ [41].

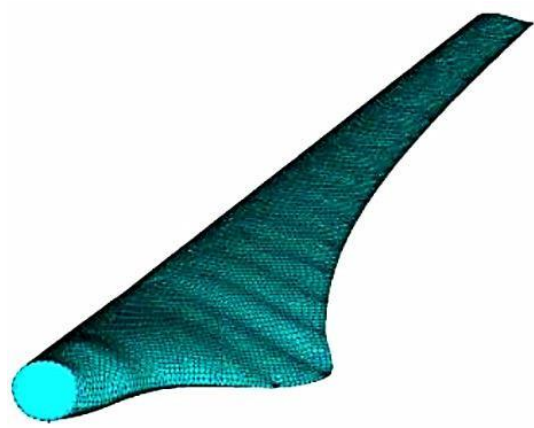

(a)

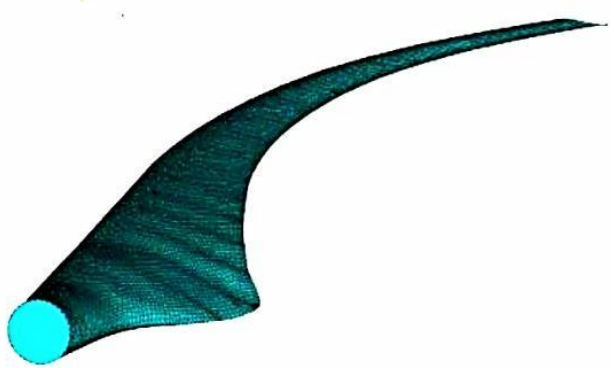

(b)

Fig. 4 Models of, (a) straight-edge blade; (b) swept-edge blade [41].

CFD simulations have also been carried out on HAWT model at different sweep directions for blades. The results showed that downstream swept blade (which has been defined as downstream depending on wind direction) achieved higher $\mathrm{Cp}$ compared with straight blade at low and medium wind speeds but this improvement is accompanied by an increase in thrust [42]. 
In experimental and numerical results for two HAWT blade models, namely slotted and tubercle designs, the results showed that slotted blade (Fig. 5-(a)) produced more power compared to the straight blade at low wind speeds .This is because slotted design introduces an internal flow within the blade, creating a separation of flow from the surface which reduces the fluid velocity. Reduction in flow velocity increases the pressure underneath the blade, thus generating more lift. As a result, tubercle model design (Fig. 5-(b)) showed a significant reduction in power at the same wind speeds. But on the other hand, it has good behavior in unstable conditions and high wind speeds. This is mainly due to its configuration of tubercle shape suppresses the turbulence wake at the trailing edge [43].

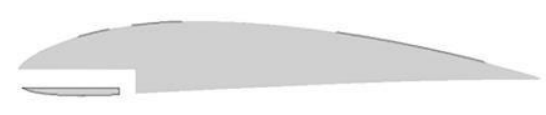

(a)

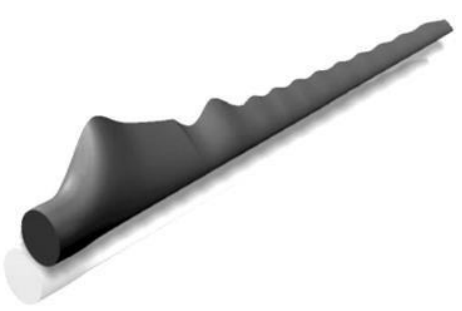

(b)

Fig. 5 HAWT blade models, (a) slotted blade section; (b) Trailing Edge Tubercle Blade [43].

Based on a numerical investigation of a modified 2D S809 airfoil to analyze the effects of location, slope angle and width of slots, the best configuration was determined considering K- $\varepsilon$ turbulence model with standard wall function as a compromise between accuracy and computing time. Depending on $\mathrm{C}_{\mathrm{L}} / \mathrm{C}_{\mathrm{D}}$ and lift to drag ratio as comparison parameters for different configurations, the result showed aerodynamic performance improved for a limited range of attack angles. However, the final configuration of slot leads to an increase in the drag force at low angles of attack, leading to less airfoil efficiency compared to the baseline configuration. On the other hand, the slot configuration showed a high performance compared with baseline at medium and high angles of attack in range of $10^{\circ}-20^{\circ}$ [44].

In the investigation of aerodynamic performance for two types of HAWT blades that have similar airfoil (SD8000), one of them non-tapered constant chord length (CCL) blade while the other was tapered and twisted blade with decreasing in chord length from root to tip (BEMT) blade. Both blades are tested experimentally in (ABRI wind tunnel). From the experimental test it was noted that maximum power coefficient $\left(\mathrm{C}_{\mathrm{p}}\right)$ for $(\mathrm{BEMT})$ blade increased by $56.33 \%$ than $(\mathrm{CCL})$ blade While 3D CFD simulation showed increasing in $\left(\mathrm{C}_{\mathrm{p}}\right)$ for (BEMT) blade by $57.66 \%$ than (CCL) blade for same conditions of wind speed and tip speed ratio. This increase in $\left(\mathrm{C}_{\mathrm{p}}\right)$ is attributable to the absence of flow separation for (BEMT) blade at optimum tip speed ratio, while flow separation happen for both blades at low tip speed ratio. Where the experimental test provided to agree with CFD simulation by low Reynolds SST k- $\omega$ turbulence model at different wind speed and tip speed ratio [45].

In addition, to improve wind turbine power, selecting an airfoil with higher $C_{L} / C_{D}$ for the blade section is needed. While best way to improve airfoil shape is optimization in MATLAB using Genetic Algorithm (GA) which produce a novel airfoil design that is evaluated by automatic interfacing for the highest $C_{L} / C_{D}$ ratio. There are also other methods to enhance aerodynamic performance of a HAWT rotor by combining GA for optimize the airfoil shape and torquematched method (TMASO) for optimise chord length and pitch angle. The optimization showed an increase in Cp up to $11 \%$ with decreasing corresponding TSR by $30 \%$ and reduced tip loss effect [46].

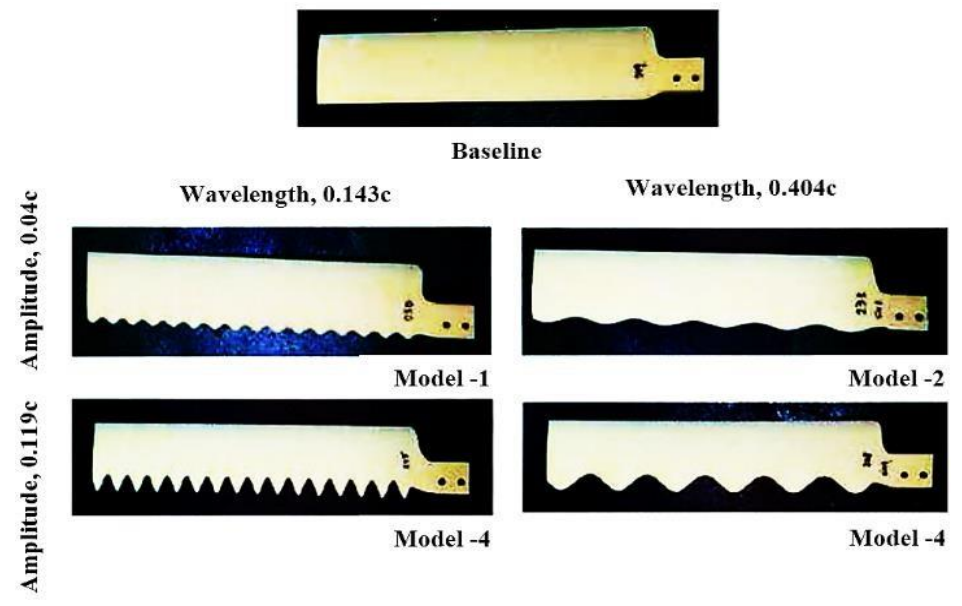

Fig. 6 The baseline and modified turbine blades with sinusoidal leading-edge [46]. 
Far from blade shape design, the blade materials are one of the factors that affected the performance of wind turbine blade. Where a lightweight blade is rotated within a lower wind speeds range and less load compared with a heavy blade. So, the static analysis of ANSYS by V. M. Kumar et al [47],showed better results for epoxy carbon material compared epoxy to glass with regard to total deformation, directional deformation, equivalent stresses, normal stresses and shear stresses .

Most of the above techniques improve the performance of the wind turbine by a small percentage, as it has not reached a convincing investment of energy content stored in the wind, so it is necessary to focus on more efficient and less complex concepts to invest more of wind energy to augment more turbine power especially for HAWT.

\section{Diffuser Augmented Wind Turbine (DAWT)}

The concept of diffuser augmented wind turbine system is introduced to increase the power of wind turbine by enclosing the turbine by a duct (shroud). Since wind power is directly proportional to the cubic of free stream velocity of wind where increasing wind velocity through the rotor plane leads to increase wind turbine power. Thus if the turbine is shrouded by diffuser to capture wind deliver to the rotor, more power will be produced for a given turbine diameter and wind speed thus exceeding Betz limit [48]. In other words, performance increase of DAWT is proportional to the mass flow through the duct and that larger performances are possible by lowering back pressure levels at the diffuser exit [49],[50].

\subsection{Historical Development of DAWTs}

The development of a DAWT started in the early 1950s, where the first works were published in Japan and England. In the first theoretical study, results showed 1.3 times higher flow velocity at the throat of the duct compared to the free stream [51]. Experiments on a small scale wind turbine with and without shroud have been conducted by M.Sanuki [52] (at 1.29 exit to inlet area ratio $\left(\mathrm{A}_{\mathrm{e}} / \mathrm{A}_{\mathrm{i}}\right)$ and total length $\left.(\mathrm{L}) 1.21 \mathrm{~m}\right)$. It has been observed that power coefficient of the shrouded turbine with three blades increased by $4 \%$ as compared with same turbine without shroud.

The theoretical results had been confirmed by experiments, which showed an increases in shrouded $\left(A_{e} / A_{i}=1\right)$ turbine performance over unshrouded one by $30 \%$. The reason for this is due to accelerating wind through the shroud and decreasing the tip losses caused by vortices [53]. A preliminary theoretical study by G. M. Lilley and W. J. Rainbird [54] based on momentum and vortex showed that a suitable design of the shroud can enhance power by $65 \%$ compared to power of an unshrouded wind turbine. This enhancement depends mainly on the shroud exit area ratio, external shape of the shroud at exit and the internal frictional losses.

A schematic drawing of the first generation shroud (shown in Fig. 7) was by researched Kogan and Seginer in 1963; this shroud was composed of a bell shaped intake, a cylindrical section to house the turbine, and a diffuser with a total angle of $8.5^{\circ}$, length $(6.82 \mathrm{D})$ and exit to throat area of 3.5. Experimental tests of several types of screen meshes to simulate the pressure drop across an operating rotor, using a relatively small wind tunnel (test section of $60 \mathrm{x} 90 \mathrm{~cm}$ ), show that the optimum turbine load factor falls within the range of 0.18 to 0.22 , and that a power augmentation factor of 3.5 at a yaw $30^{\circ}$ and 3 in case of no yaw [55]. The performance study of different concepts for wind turbines was done by [56] using 1-D momentum theory and actuator disc model. The study concluded that a ducted wind turbine which its exit area ratio exceeds 1.54 have power coefficient larger than a bare turbine in case consider the performance based on rotor diameter.

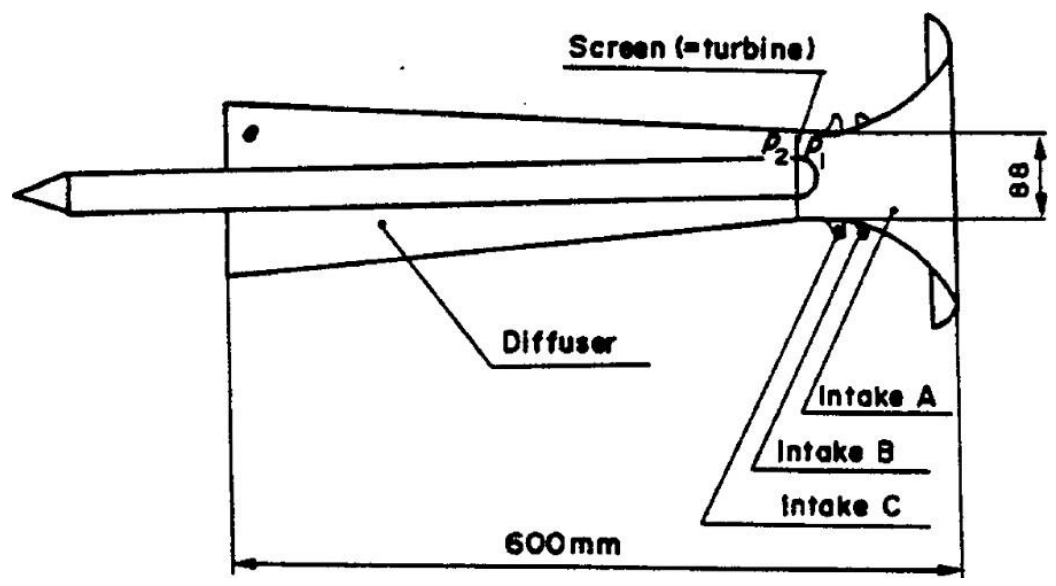

Fig. 7 Layout of the first generation shroud [15]. 
Igra [15] studied steady, one-dimensional flow arguments, and similarly showed an augmentation, in power output for a DAWT compared to that of an ideal conventional bare turbine. The second shroud model (model-A as shown in Fig.8) tested had the same intake and cylindrical section as the first generation model [50] but it had a shorter diffuser with a total angle of $12.5^{\circ}$. In order to increase the exit-area-ratio, and therefore augmentation, up to three ring-shaped flaps (same NACA 1412 cross-sections and a chord equal to $10 \%$ of the total shroud length) were placed at the diffuser exit. Screens with disc loading coefficients of $0.21,0.23$ and 0.43 were used, however, Igra suggested an optimal value was not reached as lower disc loadings were not examined. At the lowest disc loading, the peak augmentation of 2.8 was achieved for Model A with three flaps. This second generation of shortened shrouds, therefore, presented a significant improvement in the cost of energy. The overall length-to-diameter ratio of 3.64 was nearly half that of the first generation design whilst the augmentation was maintained as a result of increasing the exit-area-ratio by a third to approximately 10 through the use of multiple exit flaps [15].

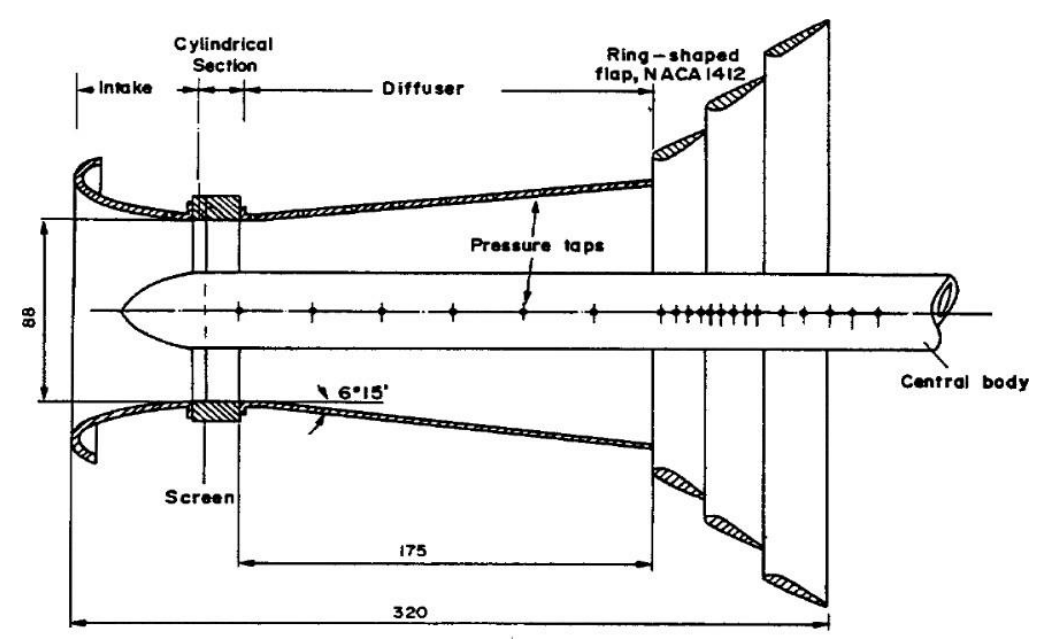

Fig. 8 Layout of the short shroud, Model-A [15].

Igra took a step change in research in moving to the third-generation design (1976) on diffuser augmented wind turbines with a shroud having NACA 4412 airfoil section with an additional circular flap of the same cross-section as shown in Fig. 9. The turbine was again modelled with mesh screens and the shroud had an $88 \mathrm{~mm}$ diameter throat and a total length to diameter ratio of 3.07. He used a larger wind tunnel with a $3.6 \mathrm{~m}$ by $2.6 \mathrm{~m}$ test section to avoid the $11 \%$ blockage he had in his previous experiments. In addition to base model (Model B), three further models (C(i), C(ii) and $\mathrm{C}(\mathrm{iii})$ ) were examined and resulted in a maximum augmentation factor of 2.26 with the turbine having an exit to throat area ratio of 8.33. The maximum augmentation factor was 1.69 for the shroud without the circular flap having a length to diameter ratio of 2.27 and an exit area ratio of 4.37. Having reduced the blockage and wall effects, the performance of the shrouded turbine - unlike for Kogan and Seginer (1963) - decreased in yaw operations. The performance reduction was slow for yaw angles up to $10^{\circ}$ but became rapid for larger angles. After performing experiments with gauze screens to simulate turbine rotors [15].

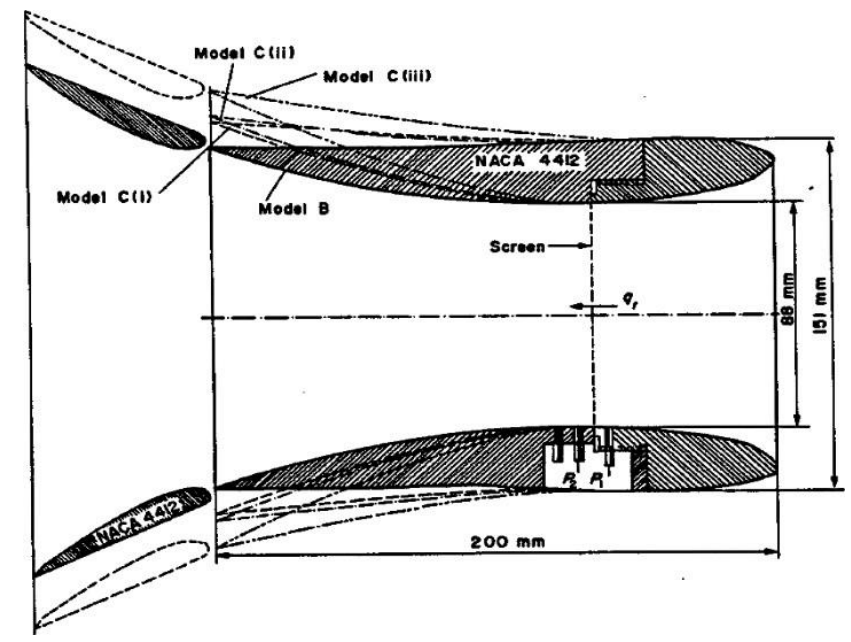

Fig. 9 The annular wing shrouds of models B, C(i), C(ii), and C(iii) [15]. 
By applying momentum theory to wind energy concentrator systems (shrouds, tip vanes, and tornado systems) were made a general conclusion that only a shroud can make a considerable improvement to the performance of a wind turbine [20]. Also, the theoretical expression for power coefficient by axial momentum theory with compared as an actuator disk model in a CFD proved that the output power for shrouded turbine more as compared to a bare turbine [57]. This increase in power can be explained through field test that had been conducted for a ducted wind turbine with $3 \mathrm{~m}$ of rotor diameter, 2.67 length to diameter and 4 of exit area ratio. Power coefficient based on the rotor diameter was 1.40 at a wind speed of $5 \mathrm{~m} / \mathrm{s}$. These increase in performance was due to reducing the flow separation that occurred in wind tunnel [58].

A simple analytical ducted wind or water turbine model based on classical fluid dynamic theories without empirical elements by Werle and Presz [59]. This model concluded theoretically that the turbine with duct (based on predict performance of flow in empty duct) have more power than the bare turbine. Fig. 10 shows the resulting influence of the duct force coefficient $\mathrm{C}_{S}$ on the maximum-power coefficient at the attendant area and velocity ratios.

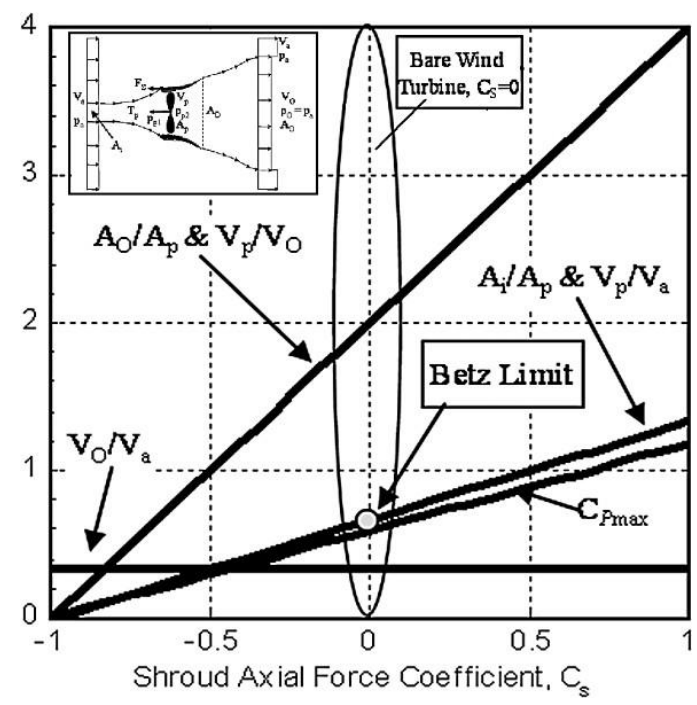

Fig. 10 Wind turbine at maximum power [59].

In the economic investigation to develop a compact diffuser for HAWT using axial momentum theory, the ratio of diffuser exit area to inlet area has been assumed at 2.75 for the baseline point design. The results showed that the ratios less of baseline design ratios, expected to decrease augmentation factor with lower cost relatively. While larger ratios increasing the augmentation factor with more cost. All these works concluded that DWT is an economic concept for small wind turbine if the diffuser fabricates by a light fibreglass [60].

At thermo-economic analysis of shrouded HAWT by F. A. Al-Sulaiman and B. S. Yilbas [61] with three different area ratios (outlet to throat area) of the shroud which were 1.5, 1.3 and 1.1. The result showed that increasing the shroud area ratio to a certain extent (without flow separation) leads to improving turbine performance and decreasing the cost of power produced. Also the study reveals that the produce power cost decrease as high wind speeds presents. In the same context, after two years F. A. Al-Suleiman conducted exergoeconomic analysis of an ejector-augmented shrouded HAWT depending on ejector inlet area ratio $r_{s}$ (ratio of the area at ejector inlet side to the area at the exit of primary shroud). The big part of study was focused on effect of $r_{s}$ with three different values on the rate of power producing and cost of its producing. The result has been shown an increase in power produced and decreases the cost of power produced by increasing the ejector inlet area ratio[62].

Moreover, A discussion by A. Kumar [63] on the use of duct for increases wind velocity in wind turbine conclude that the ducted turbine rotor can accomplish high value of power coefficient which has crossed Bet'z limit .However, the design of duct should be optimized as per different flow condition locally and globally. It has been observed that the augmentation not only improve the performance of the turbine, but also it overcomes the problem of attacking debris. As an application of diffuser shroud results in a significant reduction of wind turbine noise (blade-tip noise) and improves safety against broken blades [64].

Consequently, in recent years, several studies have focused on the development of DAWT concept Fig.11[28], particularly the optimal design of wind turbine shroud and the best way to increase the power. 


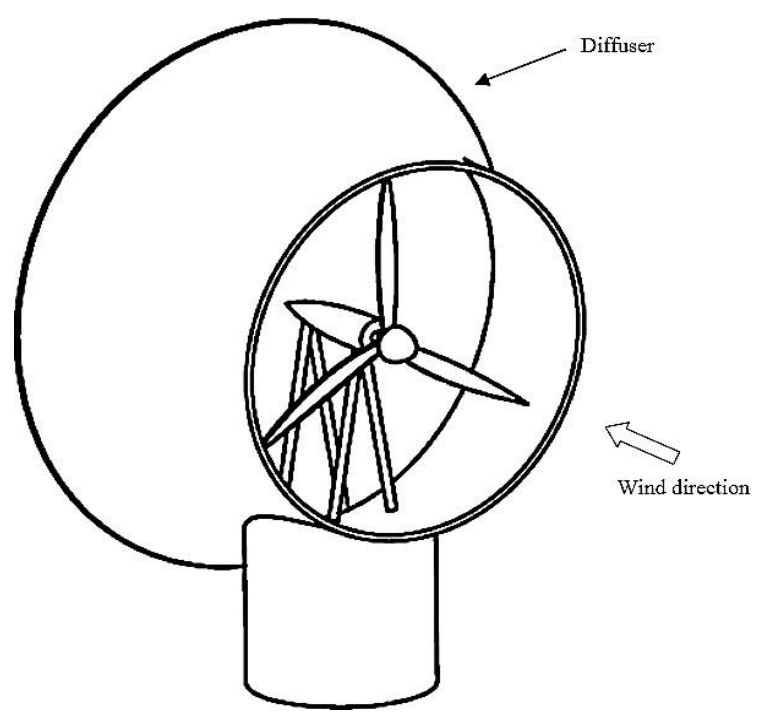

Fig. 11 Schematic of a ducted wind turbine (DAWT concept) [28].

The performance enhancement of a Diffuser Augmented Wind Turbine depends on several factors including the diffuser shape and geometries, blade airfoils, and wind condition at the mounting site. The Geometric features are the main parameters controlling the aerodynamic performances of this wind-energy device. The geometry of DAWT are denoted by dimensions of diameter of inlet diffuser which is related by rotor diameter (D), diffuser length (L), diffuser angle $(\alpha)$ and brim height (flange height) $(\mathrm{H})$ as shown in Fig. 12 [65]. Each one of these geometrical parameters has a direct or indirect effect on DAWT performance.

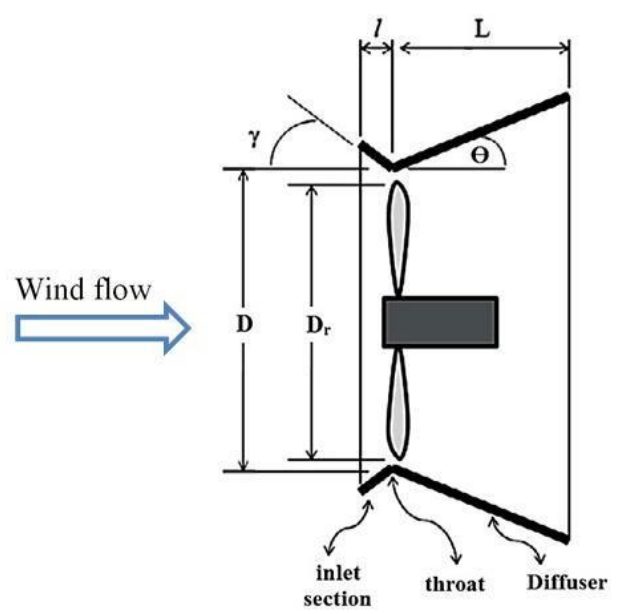

(a)

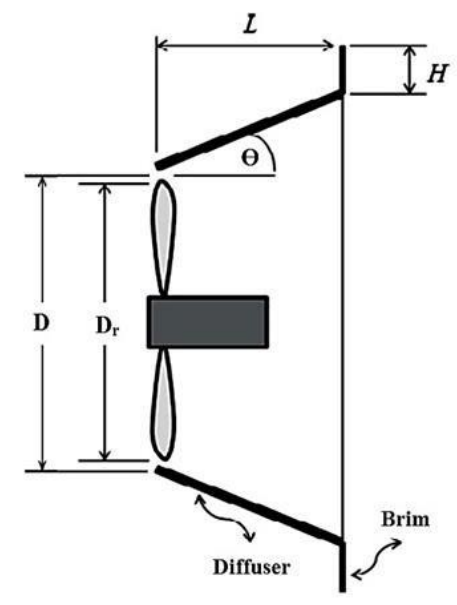

(b)

Fig. 12 Typical shroud designs for wind turbine: (a) nozzle-diffuser; (b) diffuser-brim shroud [65].

\subsection{Shape Design and Mechanisms Investigation of DAWT}

\subsubsection{Shape design}

Different configurations of DAWT were presented by the researchers to increase the power, where some of them focused on the study the effect of diffuser shape design, turbine position, number, and shape of turbine blades.

In Fig. 13 shows a horizontal axis wind turbine with a rotor diameter of $453 \mathrm{~mm}$ and 4-blades connected to hub with a diameter of $109 \mathrm{~mm}$. The turbine has been shrouded by a diffuser with different configurations for experimental evaluation of the power augmentation ratio, where the configurations were (shrouded turbine (shrouded rotor), CAWT (shrouded rotor with collector), DAWT (shrouded rotor with diffuser) at $\left(\mathrm{A}_{\mathrm{e}} / \mathrm{A}_{\mathrm{i}}=1.67\right.$ and $\left.\mathrm{L}=0.289 \mathrm{~m}\right)$, CDAWT (shrouded rotor with collector and diffuser) at $\left(\mathrm{A}_{\mathrm{e}} / \mathrm{A}_{\mathrm{i}}=1.19\right.$ and $\left.\mathrm{L}=0.408 \mathrm{~m}\right)$ and bare turbine. The comparison among all configurations has been conducted by observed the augmentation ratio of wind speed and also from evaluating power delivered using an electrodynamometer. The result has been showed DAWT produce high power but not more than 
CDAWT where the latter increase the augmentation ratio by $56 \%$ over that of the DAWT, these increasing due to presence of collector where it accelerates the flow and increase the capturing area wind [49].

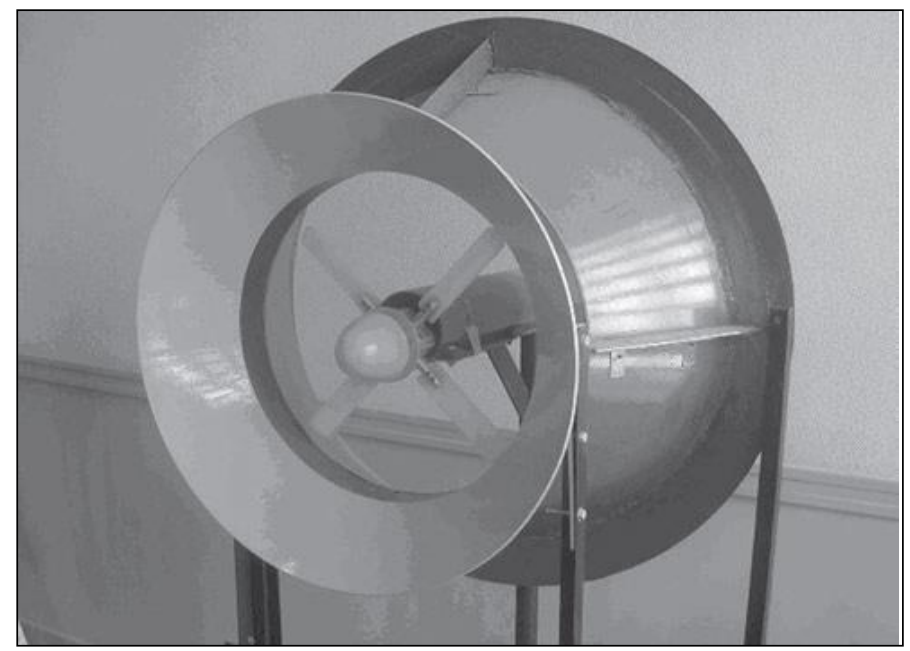

Fig. 13 The small experimental unit, showing the collector, the diffuser and the turbine [49].

In experimental study of shrouded micro-wind turbine, observed increasing of power coefficient $\left(\mathrm{C}_{\mathrm{P}}\right)$ for a micro horizontal axis wind turbine (bare turbine) up to $60 \%$ by putting a simple diffuser at $\left(\mathrm{A}_{\mathrm{e}} / \mathrm{A}_{\mathrm{i}}=1.61\right.$ and $\left.\mathrm{L}=0.12 \mathrm{~m}\right)$ around it as shown in Fig. 14-(a), while reach up to $63 \%$ by putting a nozzle-diffuser shroud around it (Fig. 14-(b)) [65].

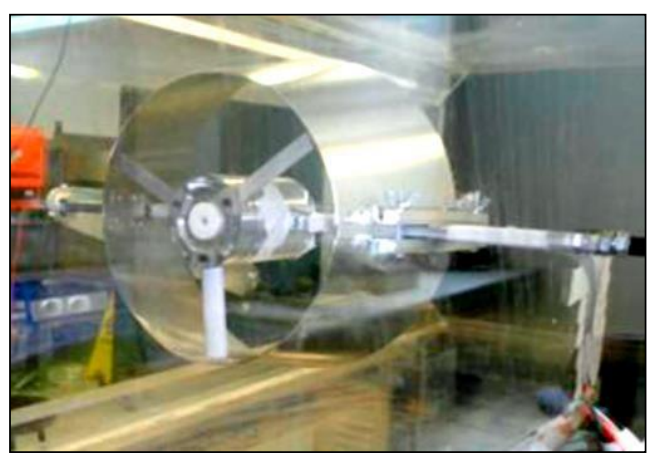

(a)

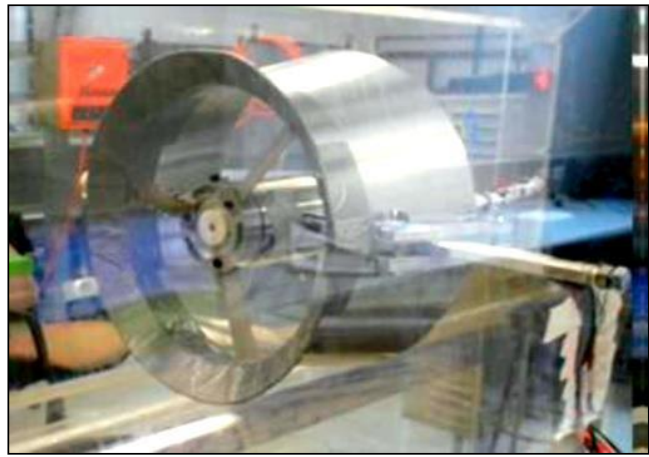

(b)

Fig. 14 Wind Turbine set-up in wind tunnel (a) diffuser augmented turbine; (b) nozzle-diffuser augmented wind turbine [65].

Converged - diverged diffuser for augmented a small-scale wind portable turbine has been numerically investigated , Where maximum wind speed at the turbine is $5 \mathrm{~m} / \mathrm{s}$. The results of CFD revealed that the diverging section parameter is more effected on diffuser performance [66]. Also, CFD Analysis of Venturi (convergent-divergent) Ducted Horizontal Axis Wind Turbine by C. D. Chaudhari et al [67] at $\left(A_{e} / A_{i}=1.5\right.$ and $\left.L=2.3 m\right)$ were carried out to investigate the effect of venturi on behavior of velocity and pressure, where a pressure difference occurs as a result of difference of the crosssection areas. At venturi section, the average and maximum velocity were found to increase to1.75 times, 2.5 times of free stream velocity respectively. Hence, the power of turbine increases by 5 times.

HAWT has been designed at $7.4 \mathrm{~m}$ of rotor diameter and shrouded by a balloon in shape of a convergent-divergent nozzle (Fig. 15). The ratio of inlet to throat area and exit to the throat are 1.31 and 1.15 respectively with 0.8 ratio of length to throat diameter. The simulation results by CFD has been showed increasing of wind speed ratio at throat area up to 1.33 at upstream wind speed $12 \mathrm{~m} / \mathrm{s}$ while speed ratio up to 1.66 at $10 \mathrm{~m} / \mathrm{s}$ upstream wind speed [12].

In addition to that, there are many experimental and simulation studies that have taken into account presence of the shroud at entrance (inlet shroud) of diffuser [64], which may have caused a significant change in flow behavior to obtain best results to increase power of DAWT [68]-[76]. 


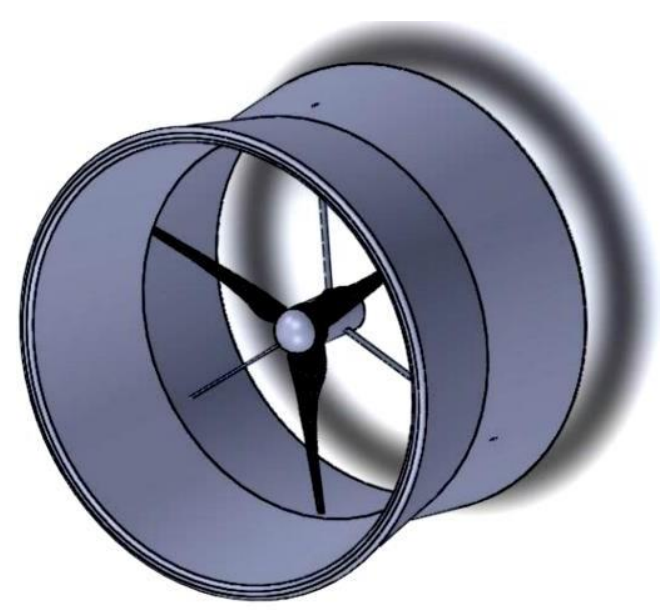

Fig. 15 Model of HAWT with shroud [12].

Simulation analysis in CFD by A. Nasution and Purwanto [77] has been implemented to investigate the different internal surface diffuser geometries, original plain surface, arbitrary curved surface and optimized airfoil geometry. The result has been showed that the use of a curvature may provide local velocity augmentation in the diffuser. This augmentation is contributed to the formation of turbulence behind the diffuser, which is indicated by excessive higher turbulence intensities. Optimized airfoil geometry, which is similar to NACA 5807 airfoil at $\left(\mathrm{A}_{\mathrm{e}} / \mathrm{A}_{\mathrm{i}}=1.01\right.$ and $\left.\mathrm{L}=0.2 \mathrm{~m}\right)$, is the one that proposed to be used as DAWT interior surface. Using this geometry, a local velocity augmentation can achieve $65.5 \%$ in comparison to diffuser with plan surface.

In a 3-Dimensional numerical simulation, a high-lift airfoil S1223 shape was considered for shroud geometry of wind turbine. RANS model has been used to verify of computations, and improved accuracy of results by using transition model. The shrouded geometry with high-lift Selig S1223 airfoil enhances mass flow which leads to improved power up to 1.93 times, which is greater than shrouded geometry within baseline NACA 0006 airfoil compared with bare turbine [78].

Multi-element DAWT with three layers cross-sectial (Fig. 16) was designed at high lift airfoil . power augmentation exceed 50\%, in addition to power enhancement, the multi-layer diffuser provides extra benefits especially for a small wind turbine in all areas, like decreasing the noise of rotor especially if the turbine designed at low tip speed ratio.but on other hand design of this type of diffuser is costly [79].

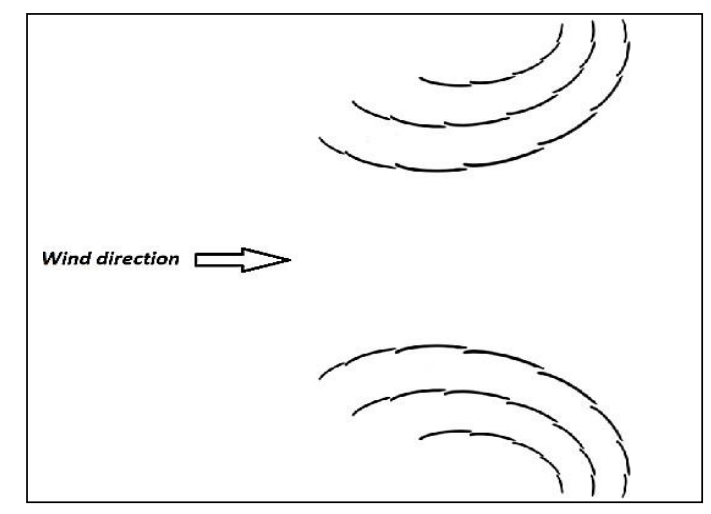

Fig. 16 Schematic section view of multi-element DAWT [79].

A primary model of a tubular divergent-truncated cone with (Ae/Ai=2.4 and $\mathrm{L}=0.171 \mathrm{~m}$ ) in different modified shapes for $(\Theta)$ ranged of $0-45$ (Table 1). An investigation for all models has been performed by CFD to identify the optimal shape to improve the energy efficiency. The numerical result was compared with wind tunnel experimental data for the primary model (model $\mathrm{T})$. The simulation result showed that maximum increases of upstream wind velocity was obtained by model $\mathrm{T}$ which was about $60 \%$. Thus the possibility of using model $\mathrm{T}$ in energy production system to bring with it an advantage of the increase in wind speed [80]. Depending upon the analytical study included an optimized configuration of a Ducted Wind Turbine with ejector type assist for the exhaust (Fig.17), may getting Power Coefficients up to 0.6. This corresponds to the output of nearly 15 conventional unducted wind Turbines (with a typical $C_{P}=0.4$ ) where numerical simulation in two dimensional by CFD used to investigate that [81]. 
Table 1 Primary and modified models of tubular divergent-truncated cone [80].

\begin{tabular}{|c|c|c|c|c|c|c|c|}
\hline Specification & Primary model & $\theta=0^{\circ}$ & $\theta=10^{\circ}$ & $\theta=20^{\circ}$ & $\theta=30^{\circ}$ & $\theta=40^{\circ}$ & $\theta=45^{\circ}$ \\
\hline Model Name & $T$ & T0 & T10 & T20 & T30 & T40 & T45 \\
\hline Configuration & & & & & & & \\
\hline \multicolumn{8}{|c|}{ Note: $\theta$ is the inclination angle used for modified models design: } \\
\hline
\end{tabular}

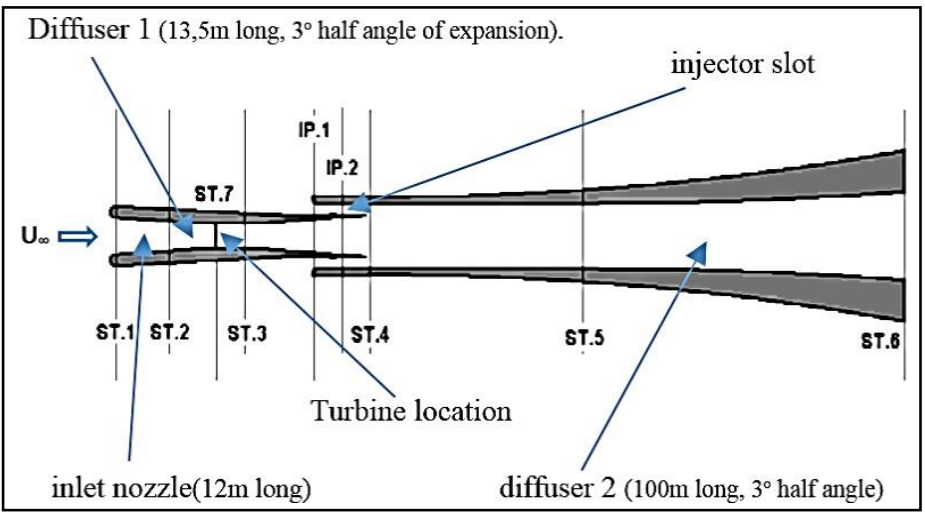

Fig. 17 The ejector assisted diffuser geometry [76].

CFD simulation was performed on Diffuser Augmented Wind Turbine by investigating effect of wind speed to develop the suitable diffuser for wind turbine at different concepts (Fig.18) of flanged diffusers as flanged diffuser with inlet shroud (a), diffuser with small inner diffuser splitter (b), cone shape splitter inside diffuser (c) and Double Diffuser with cone shape splitter (d). The redeveloped design of diffuser with small inner diffuser splitter concept showed increases in wind speed by $61.25 \%$ at diffuser opening angle of $16^{\circ}$ with $0.5 \mathrm{~m}$ and $4^{\circ}$ length and opening angle respectively for the splitter that coupled within the main diffuser [82].

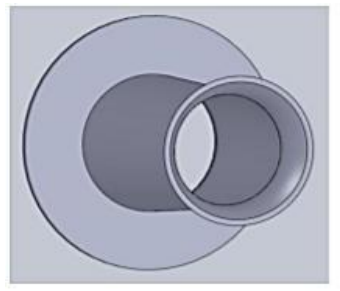

(a)

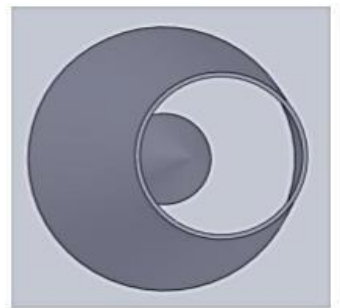

(c)

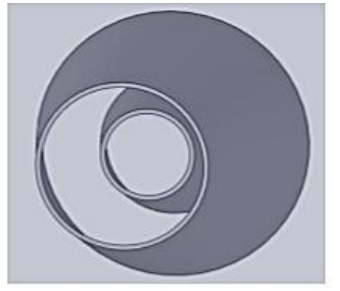

(b)

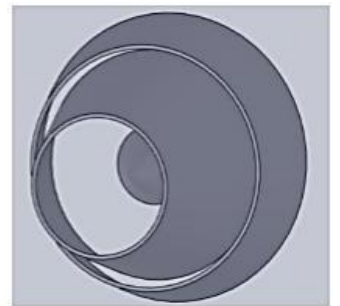

(d)

Fig. 18 Different concepts of diffusers for DAWT, (a) flanged diffuser with inlet shroud, (b) diffuser with small inner diffuser splitter, (c) cone shape splitter inside diffuser, (d) Double Diffuser with cone shape splitter [82]. 
A developed untypical multi-blade wind turbine manufacured from a composit material by using winding technology is shown in (Fig. 19-(a)). This turbine was placed in a diffuser (Fig. 19-(b)) and was simulated in CFD . The analysis results showed that enclosing this turbine in a duct increases power 2-3 times of unducted turbine [83].

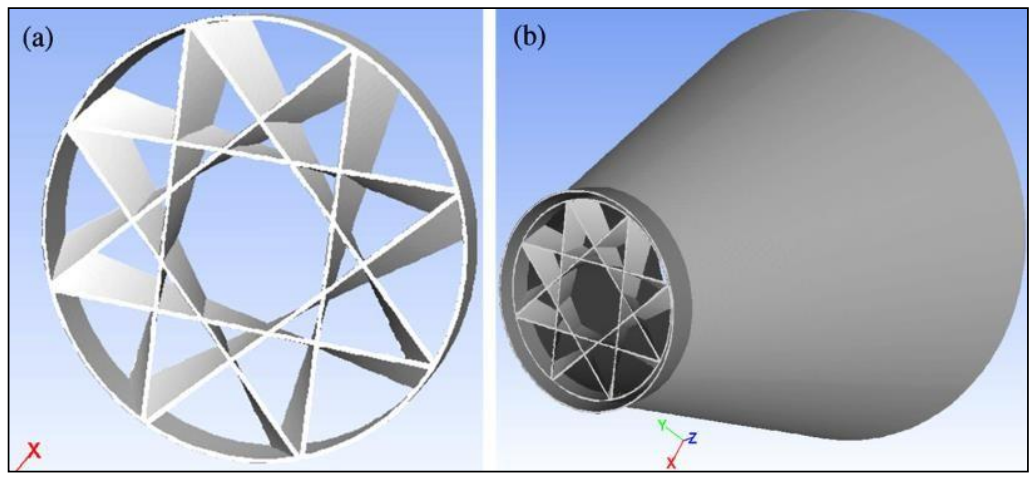

Fig. 19 Model of (a) Multi-blade bare turbine and (b) ducted Multi-blade turbine [83].

The effect of a simple step inside wind turbine duct (at $A_{e} / A_{i}=1.2$ and $L=0.755 m$ ) with three different positions as in Fig. 20 at (inlet, middle, and outlet) of the duct were numerically investigated using CFD and the result were validated with a simple duct that was manufactured and tested in a wind tunnel. The numerical result showed that locating the step at the outlet of duct increased wind velocity more than other positions. In stepped duct, the pressure decreased at downstream of rotor more compare with simple duct, that leads to increase rotor torque and power generation. The maximum power was obtained when the turbine placed at inlet of stepped duct, where $\mathrm{C}_{\mathrm{P}}$ achieved from stepped duct wind turbine was $16 \%$ more than simple duct wind turbine [84].
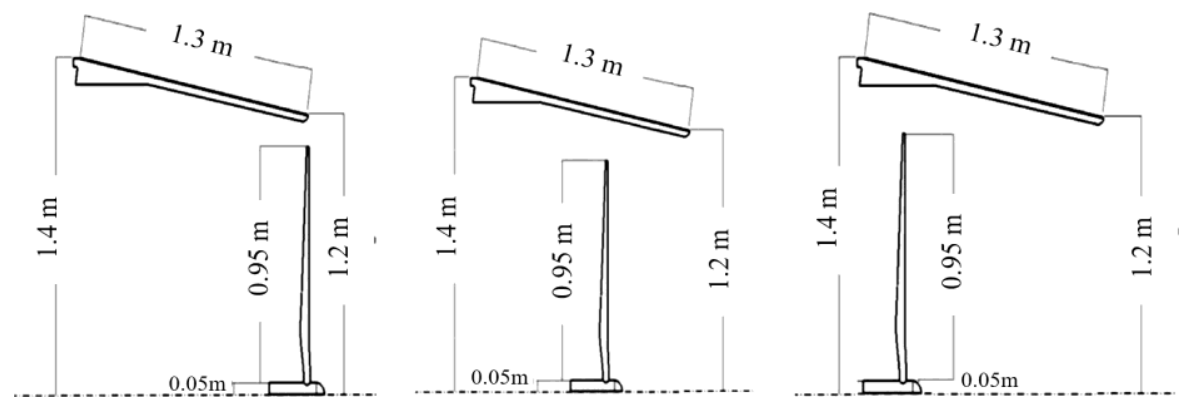

Fig. 20 Different arrangement of the rotor in the stepped duct (the flow from right to left) [84].

A ducted wind turbine with $A_{e} / A_{i}=1.33$ and $L=1 m$ ) has been studied using CFD. The study was focused on the effect of turbine blades on DAWT. It has been shown that increasing the blades number led to high torque at the start, reduce the cut-in speed and enough area to transform the energy. But on the other hand an increase of the blade count could cause high blockage in flow, hence will lead to a reduction of the coefficient of power. Thus, to get optimum performance for DAWT, the number and design of the blades should be chosen appropriately [85].

Three types of rotors with (2, 3 and 4) blades with different kinds of the blades were designed, which are wide bottom (WB), constant width (CW) and Wide top (WP) as shown in Fig. 21. An experimental investigation for all types of rotors were done within and without duct in wind tunnel where the duct was $\left(\mathrm{A}_{\mathrm{e}} / \mathrm{A}_{\mathrm{i}}=1.2\right.$ and $\left.\mathrm{L}=2.4 \mathrm{~m}\right)$. The results showed that rotational velocity increased by increasing attack angle from 0 to 75 , where maximum rotational velocity at an angle of attack 75 and it was zero at 0 and 90 angles. The rotational velocity decreased by $10 \%-12.5 \%$ for each blade added with the increase in torques, where the blockage is the cause behind this reduction which is larger in ducted turbine compared to bar turbine. The rotors with (WP) blades were lower rotational speeds, turns out that blades number and its design are interrelated, so both parameters should be considered to obtain appropriate rotor. The duct increases rotational velocities of rotors reasonably in terms of blade design and blade numbers. Moreover, this type of turbine can be used in areas with low velocities [86].

A two and three brimmed DAWTs were introduced and experimented in a multi-rotor system (MRS) by Göltenbott et al [50], they were spaced side-by-side (Fig. 22) in close vicinity in the same plane normal to a uniform flow where the length of each one was $0.07 \mathrm{~m}$. Power was noted increased up to $5 \%$ at gap ratio between neighboring brims $(\mathrm{s} / \mathrm{D})=0.5$ 
and $9 \%$ at(s/D $=0.15)$ for the two and three rotor configurations are respectively in comparison to a single rotor system DAWT (SRS).
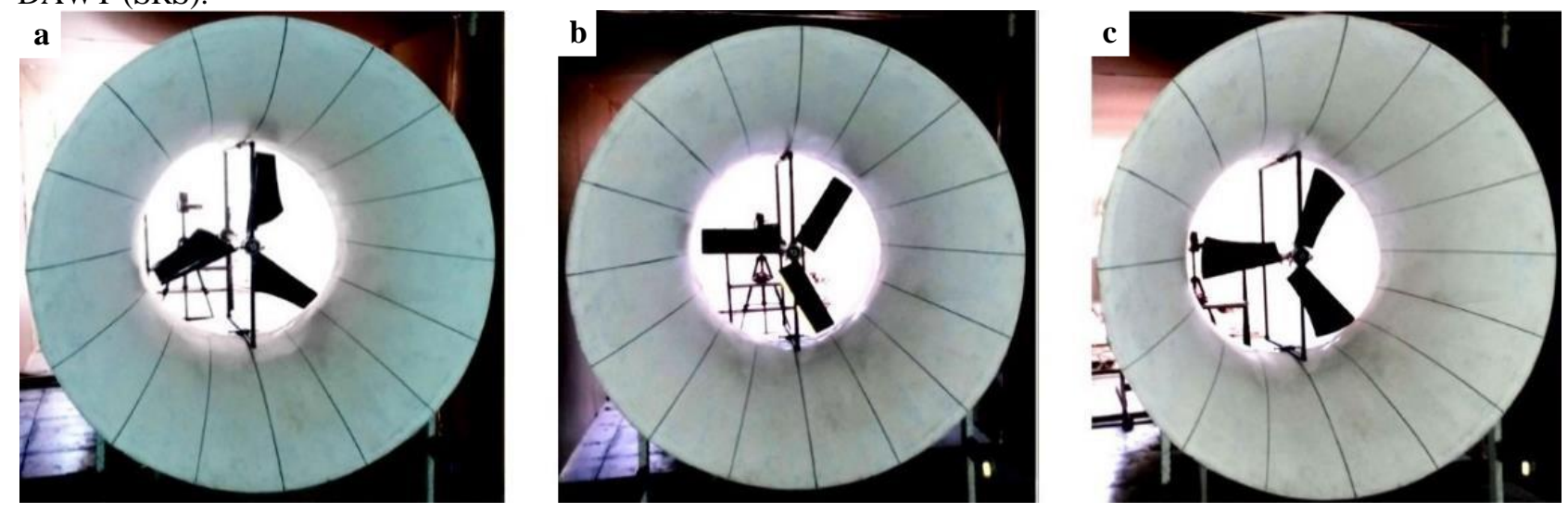

Fig. 21 Three bladed rotors at the throat of duct (a) WB; (b) CW; (c) WP [86].

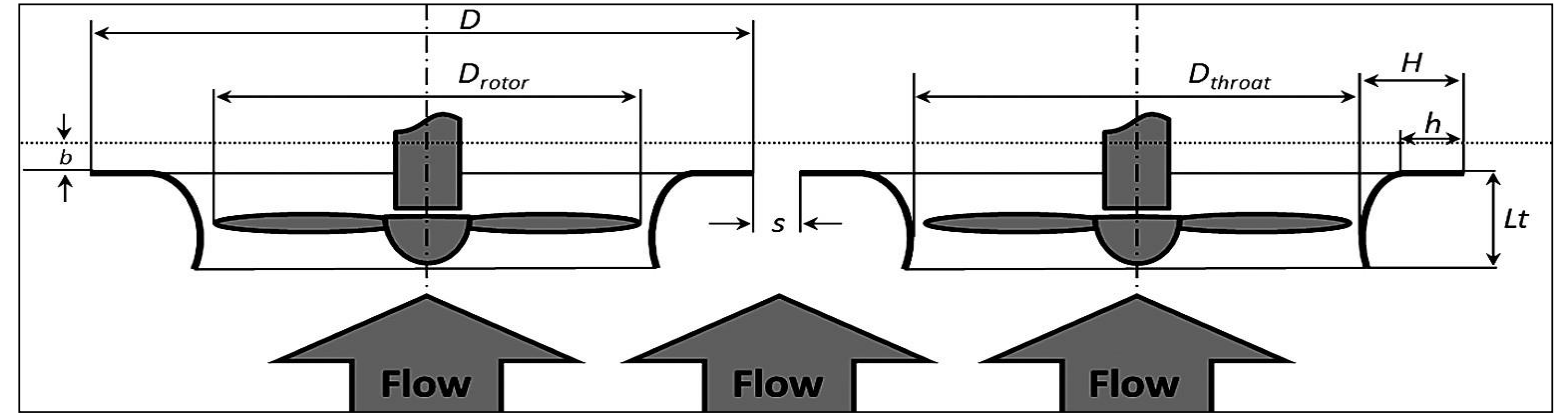

Fig. 22 Schematics of two brimmed DAWTs placed side-by-side (top view) [50].

\subsubsection{Mechanisms investigation of DAWT}

The mechanism and conditions of investigation DAWT are considered of the important factors to satisfy power augmentation, through which data for the flow mechanism is obtained and the approximate forecast of improvement in DAWT performance, whether the investigation was analytically or practically.

In a wind tunnel experimental in the Institute of Turbo machinery, Lodz University of Technology which carried out tests on DAWT $\left(\mathrm{A}_{\mathrm{e}} / \mathrm{A}_{\mathrm{i}}=1.07\right.$ and $\left.\mathrm{L}=0.54 \mathrm{~m}\right)$ by using pneumatic measurement and Particle image velocimetry (PIV) cameras and observed that an increase in CP of up to 70- 75\% compared with a bare rotor [75].

A CFD simulation for DAWT to investigate of determination of model size influence on flow blockage effects by Kulak et al [87] for a different range of model sizes. The examined model sizes included: D_5, D_10, D_20, D_30, D_80, and D_real, where the number represent the blockage coefficient (ratio of the frontal projection area of the diffuser with flange/area of the wind tunnel outlet). The numerical study was involved comparison of obtained results with available experimental data by Olasek et al [75] for D_5, D_30, and D_80 models. The results as shown in Fig.23 have been showed that D_80 has drag force value falling out of the general trend while D_30 size near to similar the diffuser D_5 and D_real, separately, where the relative difference in a range of $2 \%-3 \%$. A $1 \%$ to $3.5 \%$ was the ratio of contribution of viscous forces in total drag on investigated diffuser sizes D_5, however, may not allow manufacturing the rotor blades with acceptable quality. The drag of the D_30 diffuser is sensitive in an insignificant degree to change of velocity, therefore, the effect of scale does not influence the results in appreciable extent, it is then confirmed that D_30 model size, with minor corrections, can be represented in regards to up-scaling the measured loads to 1:1 size.

Four small HAWTs (Ampair 300) were located in each opening with a $3 \mathrm{~m} \times 3 \mathrm{~m}$ cross-section area. A compact diffuser was also integrated with the turbines for further flow enhancement. It was shown by CFD analysis that a ducted area prevents flow from bypassing the turbine and increases the flow rate passing through its rotor which results in power generation augmentation. Performance of HAWT was increased by $30 \%$ when operating in the opening and a further $30 \%$ when the diffuser was integrated. The $C_{\mathrm{P}}$ of the diffuser integrated HAWT operating in the opening exceeded 0.5 while the $C_{\mathrm{P}}$ of the bare HAWT in free stream is around 0.25. Power [88]. 


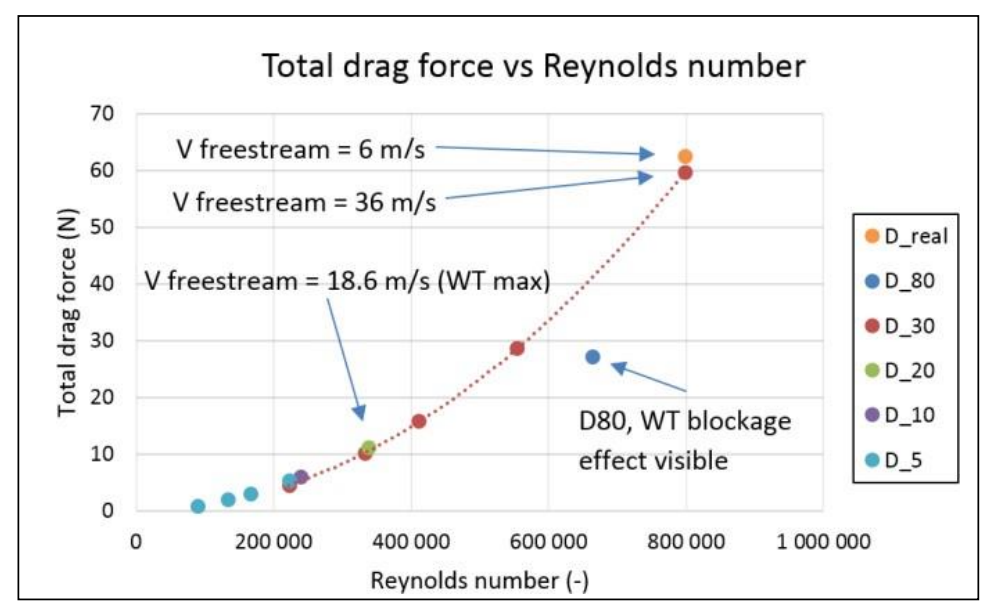

Fig. 23 Total drag force, as computed via CFD, for diffuser models in a function of Reynolds number [87].

ANSYS fluent have been applied to simulation study of DAWT at $\left(\mathrm{A}_{\mathrm{e}} / \mathrm{A}_{\mathrm{i}}=2\right.$ and $\left.\mathrm{L}=0.12 \mathrm{~m}\right)$ where the result showed increasing in mass flow and augmented in wind velocity up to $125.666 \%$ which lead to increase in power produced about 1.6 - 1.7 times where $\mathrm{k}-\mathrm{w}$ model was giving best result compare with $\mathrm{k}-\varepsilon$ model at same simulation boundary conditions [89]. Also, CFD simulation approaches were an attempt to predict of DAWT performance by two of rotor models, Actuator Disk Model ADM (The turbine is modelled in 3D as a disk or in 2D as the disk's section (rectangle)) and 3D fully resolved Rotor Model (FRM). A good correlation was shown between ADM and experiments in wind turbine power determination. Where the rotor power in experiment and FRM was defined by (torque * rotational velocity) while in ADM, it was calculated $(\mathrm{P}=$ stream flow velocity* pressure gradient * rotor volume). ADM simulation required less time about 50 times than FRM, where a coarser mesh can be applicable, and boundary condition not need to resolve it, with consideration FRM approach is greater fidelity means that ADM cannot be used straight-away for flow analysis [90].

To increase the prediction accuracy at the lowest cost for simulation, ALM (Actuator Line Model) as a modified model was proposed alongside the existing models (FRM, 2D ADM, and 3D ADM). The results of ANSYS CFX were compared with FRM by L. Michal et al [90] as a reference which has been compared with the experimental results, as in Fig. 24, ALM shows the best agreement where it predicts velocity and pressure fields at almost the same values as FRM and better than 2D ADM and 3D ADM. However, 2D ADM very good choice for fast calculation but with low accuracy, while 3D ADM is better from the latter but it is expensive computational time [91]. Also using 3D ADM to simulate the rotating blades of wind Lens turbine and observed that ADM is very good to investigate of flow around that type of turbines [73].

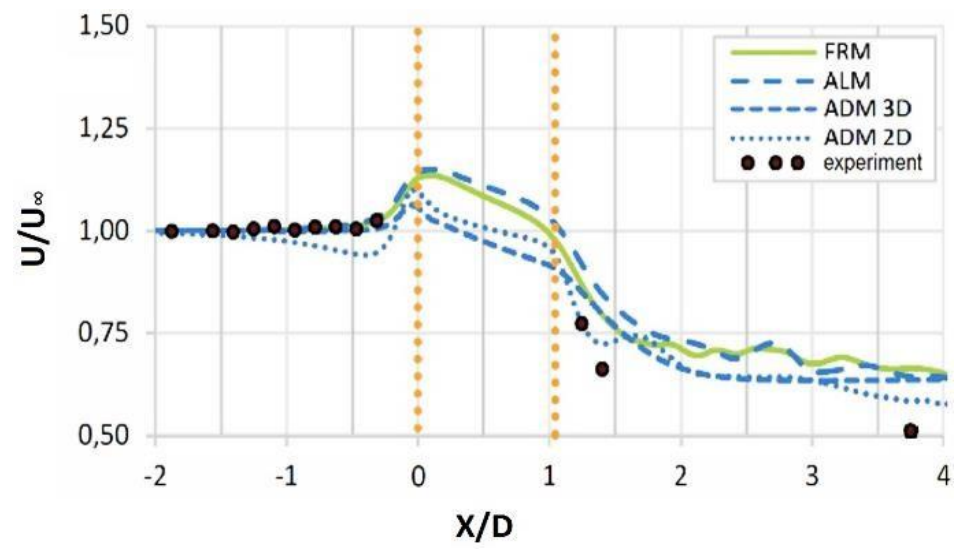

Fig. 24 Variation of $\mathrm{U} / \mathrm{U}_{\infty}$ at $\mathrm{TSR}=4.5$, dotted lines denote the entry and exit of the diffuser [91].

CFD investigation of Gurney Flaps (GF) on DAWT performance by V. V. Dighe et al [92] has been done at 2D approach with RANS equation for computing the flow, The actuator disc (AD) method is used to simulating the turbine, both numerically and experimentally, where it is allowed to mimic the desired pressure drop across the disc without modelling geometry of rotor. 
The aerodynamic performance for the modified design of wind-lens turbine (which made according to the quasithree-dimensional method for aerodynamic design of turbine rotor and Genetic Algorithm (GA) for optimizing aerodynamic of rotor blade loading distribution and the wind-lens shape) and its conventional design has been investigated with verified in a wind tunnel and numerically with 3D-RANS. The results showed, optimum design was very effective in extracting the wind power, where it is achieved high power coefficient of 0.604 which was higher than in congenital design. However, it is possible to exceed Betz limit for wind lens turbine by applying the present design method [93].

CFD simulation was done for flow fields around flanged diffusers by K. Mansour and P. Meskinkhoda [94] to study small-type wind turbines. In this calculations, Esparto Allmaras and k- $\varepsilon$ RNG models were used for solving corresponding Reynolds Average Equations. Comparison of the computed results was done with the corresponding experimental data agrees. Hence, it has been concluded that the used models have the capability of providing reasonable predictions for the complex turbulent flows. Although there are some differences between the numerical calculations and the experiment, which may be mostly due to the assumption of flow to be axisymmetric.

The effect of turbulence intensity on bare and diffuser augmented micro wind turbine (DAMWT) (Fig. 25) has been investigated experimentally at a wind tunnel by placing them downstream of a grid (at different spacing size) for range of distances $(0.1-0.3 \mathrm{~m})$ which generate turbulence in range from $2 \%$ to $29 \%$ as shown in Fig. 26 and results were compared with CFD simulation. Turbulence was found to decrease the performance of both MWT and DAMWT at high tip speed ratio or mostly at pre-stall regime where peak $C_{p}$ of DAMWT 0.22 while $C_{p}$ was 0.11 for MWT. This decreases may be attributed to the earlier transition from laminar to turbulence boundary layer and thickening of the boundary layer hence increase the drag which is not seen at lower tip speed ratio cases, where turbulence has little effect on the wind turbine performance. Finally, it can be concluded that diffuser augmented is also useful even in the case of a highly turbulent flow stream [95].
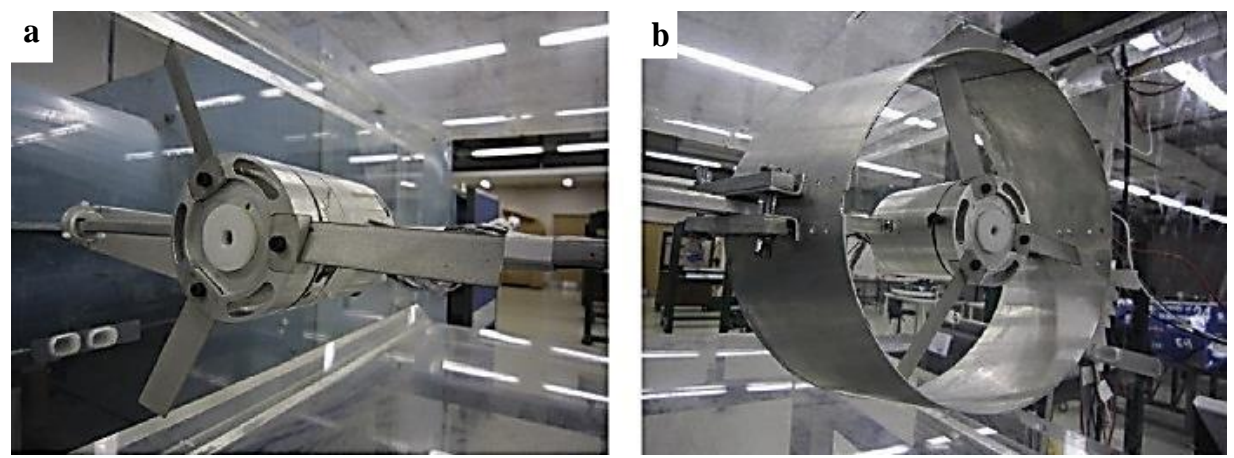

Fig. 25 A micro wind turbine, (a) Bare wind turbine; (b) shrouded turbine [95].

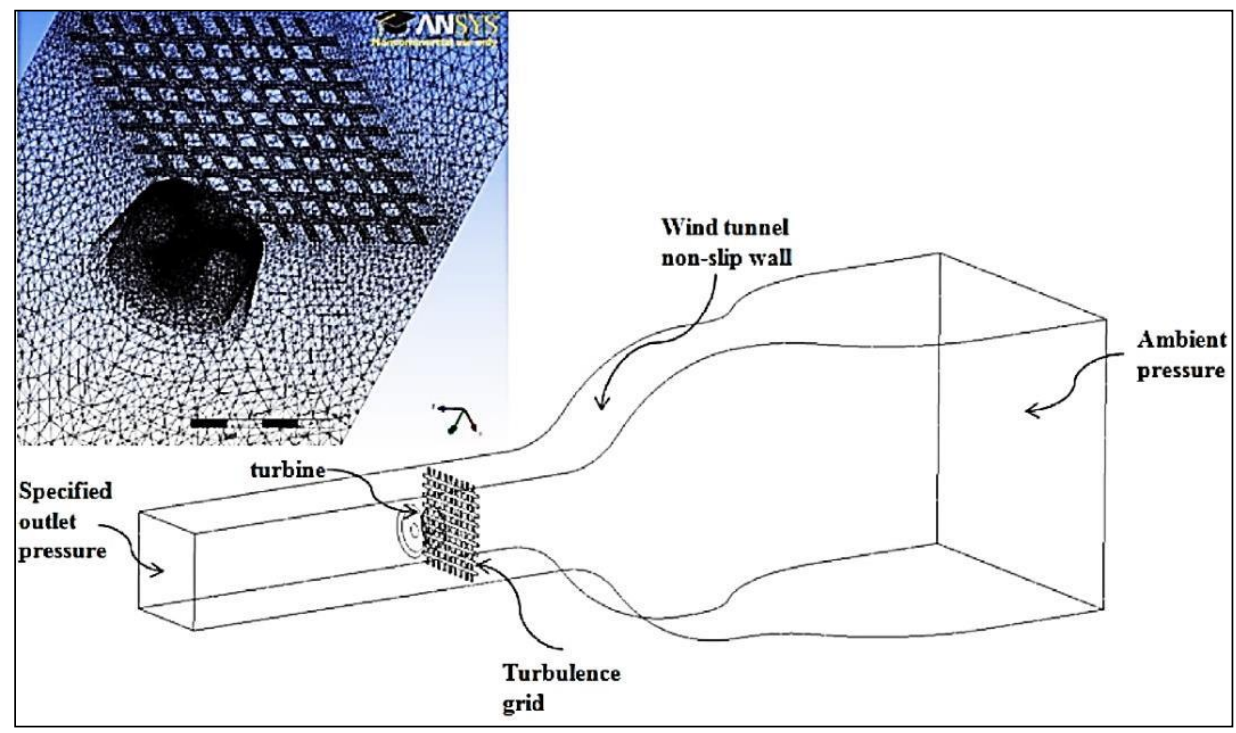

Fig. 26 CFD computational domain with turbulence grid [95]. 


\subsection{Important Geometrical Parameters for Augmentation by DAWT}

As mentioned earlier that the enclose the turbine inside a diffuser lead to increased wind speed and thus increased power, as the increase wind in speed depends on several parameters, including the length of the diffuser and the diffuser open angle, both of which affect the proportion the area of outlet to inlet ratio of diffuser $\left(\mathrm{A}_{\mathrm{e}} / \mathrm{A}_{\mathrm{i}}\right)$. Also, the flange at the exit of diffuser from the important factors which effect on augmentation of DAWT.

\subsubsection{The Effect of Diffuser Length and Angle of Diffuser on Power Augmentation.}

The length of the diffuser is usually expressed as the ratio of diffuser length $(\mathrm{L})$ to the diameter as $L / \mathrm{D}_{\mathrm{r}}, \mathrm{L} / \mathrm{D}$ or $\mathrm{L} / \mathrm{D}_{\mathrm{t}}$ where $D_{r}, D$, and $D_{t}$ are rotor diameter, inlet diffuser diameter, and throat diameter respectively. In an experimental study on micro DAWT, the tests were carried out in wind tunnel for different values $L / \mathrm{D}_{\mathrm{r}}$ in range of 0.63 to 1.47 . The result showed that increasing $L / D_{r}$ with the same diffuser open angle $\left(12^{\circ}\right)$ causes an increase of $\left(A_{e} / A_{i}\right)$. This increase led to a decrease in cut-in speed. In Fig.27, it was observed that the increase $L / D_{r}$ do not increase $C_{p}$ but only lead to increasing the tip speed ratio. Thus, as wind velocity at rotor plane increased, this indicates that the rotor should be rotate faster to enable capturing of wind energy [65].

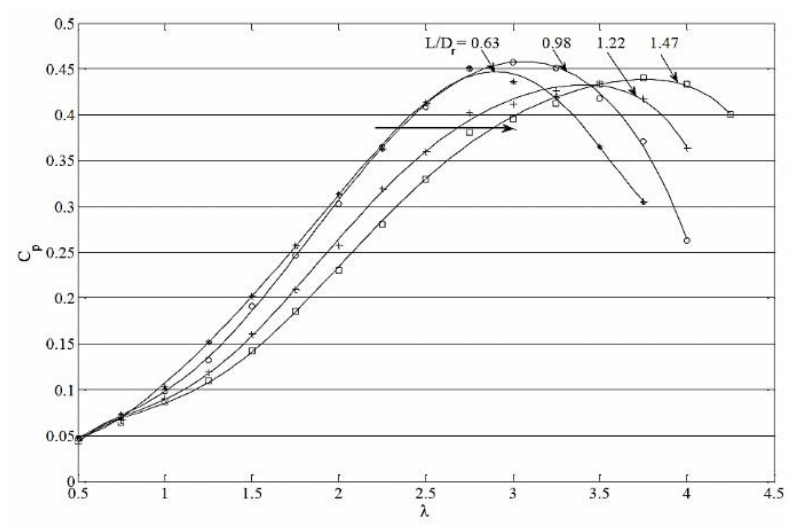

Fig. 27 The effect of L/Dr on the performance comparison of diffuser shrouded micro DAWT [65].

CFD simulation on C-D diffuser (as shown in Fig. 28) by R. A. Kishore et al [66] showed the optimum design at diverging half cone angle (open angle) $\left(\Theta_{2}\right)$ of $10^{\circ}$ and length section $\left(\mathrm{L}_{2}\right)$ equal to throat diameter $(\mathrm{D})$, while open angle $\left(\Theta_{1}\right)$ and length section $\left(L_{1}\right)$ were $15^{\circ}$ and $0.125 \mathrm{D}$ for converging section, respectively. Where the ranges of $L_{2}$ which were tested $\left(0.5-1.5 D_{t}\right), L_{1}$ range of $\left(0.125-0.5 D_{t}\right)$ and $\Theta_{1}, \Theta_{2}$ in range of $\left(0-16^{\circ}\right)$. The results showed an augmented in wind velocity up to 1.2 times of upstream wind velocity, also observe that small-scale wind energy portable turbine with a diffuser at length equal to rotor diameter produces power of $1.4-1$ times compared with the same turbine without diffuser. As well as changing angle of incident wind on a collector- and diffuser-augmented wind turbine (CDAWT) shows that it is possible to capture energy in the wind up to high angles [49].

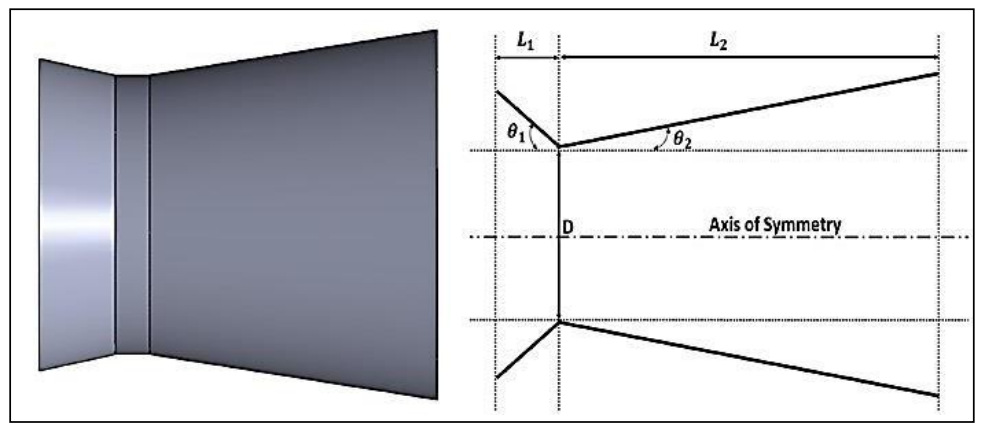

Fig. 28 An initial design of diffuser modelled using CFD [66].

Further experimental and numerical investigations have been conducted on a diffuser and DAWT with flange by Kardous et al [76] to get more details on the effect of the geometrical features on vortices site and increase in wind velocity at its inlet section. It turns out that wind velocity increase and the locations of these vortices are directly linked to the values of geometrical parameter of the diffuser (flange height $(\mathrm{H})$, diffuser's length $(\mathrm{L})$ in range of $(0.25$ to 3.25$)$ $\underline{D_{a}}\left(D_{a}\right.$, throat diameter) and open angle $(\Theta)$ in range of $\left(0^{\circ}\right.$ to $\left.\left.30^{\circ}\right)\right)$ whose best values were suggested for them as in Fig.

*Corresponding author: balasemalquraishi@etcn.edu.iq ; balasemalquraishi@gmail.com 2019 UTHM Publisher. All right reserved. penerbit.uthm.edu.my/ojs/index.php/ijie 
29 show effect of $(\Theta)$ on velocity increasing $\left(\mathrm{U} / \mathrm{U}_{\infty}\right)$ at optimum $(\mathrm{H})$ and Fig. 30 show effect of $(\mathrm{L})$ on $\left(\mathrm{U} / \mathrm{U}_{\infty}\right)$ at optimum values for $(\mathrm{H})$ and $(\mathrm{L})$, where the optimum $(\mathrm{L})$ was $1.5 \mathrm{D}_{\mathrm{a}}$ and optimum $(\Theta)$ for diffuser and DAWT were $10^{\circ}$ and $12^{\circ}$ respectively, beyond the optimal value of this parameter, the wind velocity decreases.

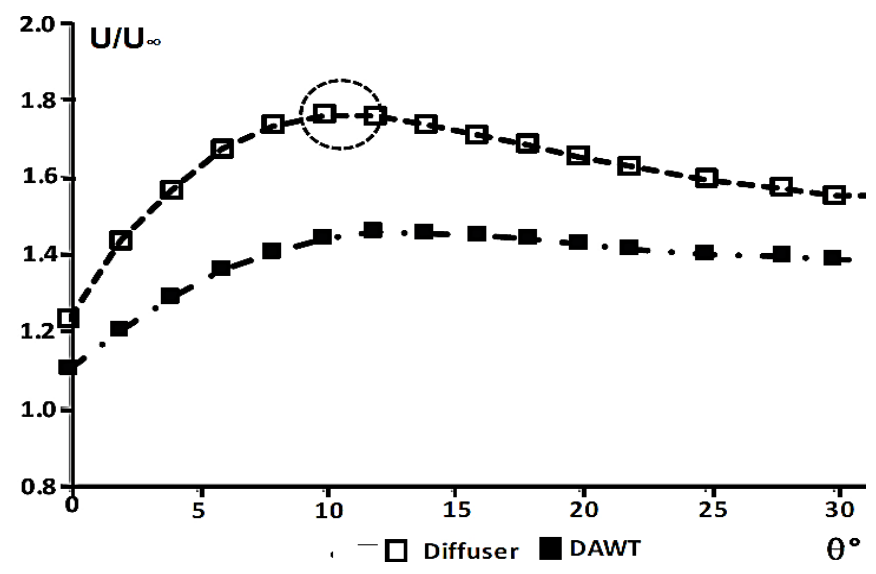

Fig. 29 Wind velocity ratio at the diffuser's throat $\left(U_{\infty} / U_{\infty}\right)$ vs. Diffuser's open angle $(\Theta)[76]$.

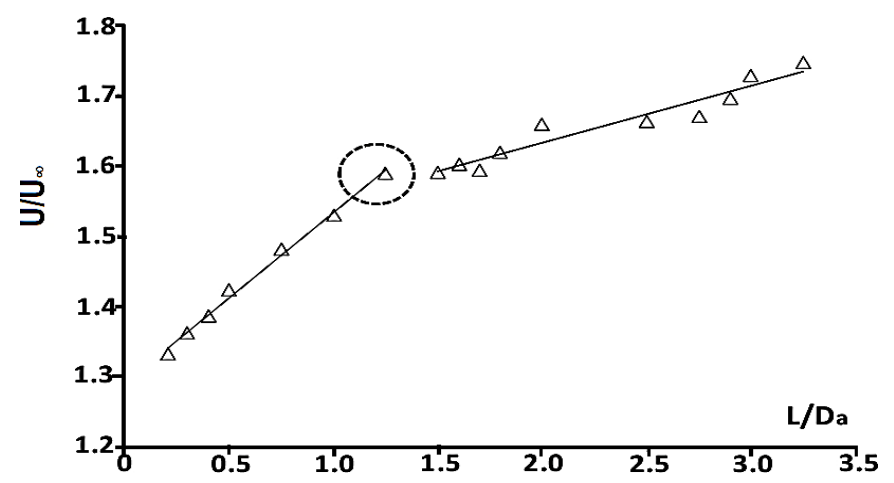

Fig. 30 Wind velocity ratio at the diffuser's throat $\left(\mathrm{U} / \mathrm{U}_{\infty}\right)$ vs. the ratio Diffuser's length to inlet section Diameter $\left(\mathrm{L} / \mathrm{D}_{\mathrm{a}}\right)$ [76].

A small wind turbine with a simple frustum diffuser has been simulated by CFD at different sizes of diffuser length (L/D) in range of (0.1-0.4) and area ratio (H/D). The results showed that increase of H/D with constant L lead to the expansion of flow through diffuser causes decreasing of downstream pressure and the suction side of rotor blades, which create lift force on the blades, hence increase the rotor power. Increase L/D also lead to increase power. Fig. 31 showed the effect of $\mathrm{L} / \mathrm{D}$ and $\mathrm{H} / \mathrm{D}$ on maximum $\mathrm{C}_{\mathrm{p}}$ where modification of $\mathrm{H} / \mathrm{D}$ is not effective beyond $(0.05-0.15)$. In other hand, the extensive increase of $\mathrm{L} / \mathrm{D}$ lowers $\mathrm{C}_{\mathrm{p}, \max }$.Hence there is an optimum length factor for a frustum diffuser [96],[97].

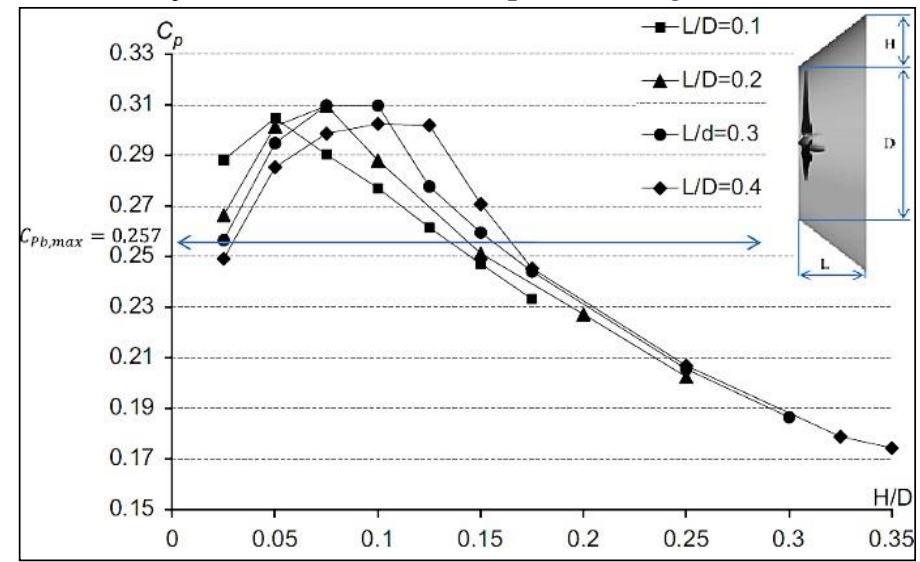

Fig. 31 Maximum $C_{P}$ of DAMWT model shrouded by diffuser with different L/D and H/D [96]. 
Four different concepts of diffusers designs have been modelled in CFD by T. S. Kannan et al [82] (as was mentioned in Fig.18) to investigate the velocity augmentation at different geometrical parameters as diffuser opening angle $(\Theta)$ and splitter angle $\left(\Theta_{\mathrm{s}}\right)$ in range of $4^{\circ}-16^{\circ}$. The highest augmented percent in concept (a) was $67.12 \%$ at $\left(\Theta=12^{\circ}\right)$. In concept (b) and (c) highest augmentation recorded at $\left(\Theta=8^{\circ}\right.$ and $\left.\Theta_{\mathrm{s}}=8^{\circ}\right)$ were $35.25 \%$ and $23.25 \%$ respectively, while in concept (d) best augmentation of $54.5 \%$ was recorded at $\left(\Theta=16^{\circ}\right.$ and $\left.\Theta_{\mathrm{s}}=16^{\circ}\right)$. In redeveloped concept, the augmented percent was 61.25 at $\left(\Theta=16^{\circ}\right.$ and $\left.\Theta_{s}=4^{\circ}\right)$. To get a better understanding of effect of the open angle on wind velocity increase at inlet section of an empty flanged diffuser and diffuser with turbine (DAWT), numerical simulations and wind tunnel experiments have been carried out by R. Chaker et al [70] on seventeen open angle ranged from $0^{\circ}$ to $35^{\circ}$. Results showed that wind velocity increases as open angle increase. The optimum angle was $10^{\circ}$ for the empty diffuser and $12^{\circ}$ for the DAWT with velocity increase of 1.76 times and 1.45 times respectively. The wind speed decreases before becoming nearly constant beyond these angles. Values of the optimum angles and therefore wind velocity at inlet section of the diffuser are strongly linked to the dynamics of two contra rotating vortices generated in the region located behind the diffuser. Indeed, whenever the open angle becomes larger than the optimum value, the vortex located nearer exit area, partially covers the diffuser outlet section. It causes the air flow to become disturbed and a recirculation zone emerges at diffuser inner wall (boundary layer separation). This phenomenon happens simultaneously with wind speed slowing down at diffuser inlet section.

Two different cases of diffuser have been simulated in a range of $0.15-0.4$ diffuser length to the rotor diameter of wind turbine $\left(\mathrm{L} / \mathrm{D}_{\mathrm{r}}\right)$ by H. M. Elbak [72] to reference the effect of diffuser length as in [82]. In one of the cases proposed a diffuser within splitter at $\left(\Theta_{\mathrm{S}}>\Theta\right)$. While in the second case proposed the flanged diffuser with inlet shroud involved a splitter at $\left(\Theta_{\mathrm{S}}<\Theta\right)$. The result of comparing of the two cases with same geometrical diffuser in each case but without splitter has been showed that the mass flow of wind enhances with an increase of diffuser length.

Numerical 2D symmetry model was used by M. Lipian et al [98] to study the sensitivity of angle and brim height of diffuser on the DAWT design in a different range of $2 \Theta$ from $0-30^{\circ}$ and brim to diffuser diameter was in a range of $(0.1,0.3,0.5)$.Augmenting these two geometric parameters results generally in the creation of two vortices - one, nearer to the stream exiting the diffuser, directed counter-clockwise, and another one - above, turning clockwise. The CFD analysis result showed the best increase in wind speed was 1.6 at an angle $\left(2 \Theta=6^{\circ}\right)$ (Fig. 32). Where the diffuser with small angles, prefer a high brim. At angles of 18-26 increased the speed acceptable. Although large angles cause separation in the flow, which may amplify the vibrations in the flow channel and the turbine, so the small brim is preferred in these cases. The sensitivity study was not identical in terms of the imposition of a constant pressure drop through the virtual rotor which is not true since at the time of the CFD study there was no experimental test of the model.

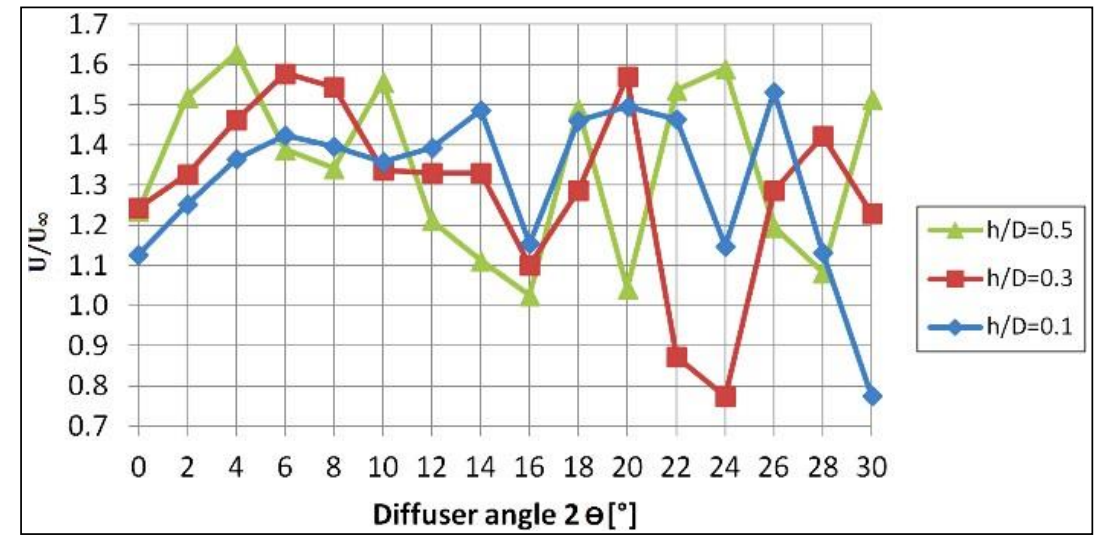

Fig. 32 Variation $\mathrm{U} / \mathrm{U}_{\infty}$ with diffuser angle at the rotor inlet for all examined geometries [98].

\subsubsection{Effect of Brim (Flange) on Power Augmentation}

The diffuser with a flange at the exit at the proper height can increase wind velocity when augmented by the power of DAWT. The presence of flange creates pressure drop at diffuser outlet due to vortex formation caused draws more wind to diffuser as shown in Fig. 33 so, flange height is considered one of the important geometric features that contribute effectively to improve the diffuser aerodynamic performances [64], [65],[68], [72], [74],[99].Also, the presence of flanged diffuser on the performance of wind turbine rotor demonstrated that significant performance benefits can be accomplished overcoming Betz limit [69], [89]. Where power augmentation of wind turbine within flange diffuser up to 4-5 times of bare turbine at the same diameter. In other hand, because of the presence of flange at the outlet of diffuser helps DAWT always to face the direction of approaching wind [64], [99]. The effect of the flange at the outlet of a diffuser is usually expressed as flange height to rotor diameter ratio (H/D) or (h/D). So, in study flange effect on performance of DAWT by B. Kosasih and A. Tondelli [60] with different H/D values as 0 (no flange), 0.15 and 0.2 in DAWT with $\left(\mathrm{L} / \mathrm{D}_{\mathrm{r}}=0.63, \Theta=12^{\circ}\right)$. They have been observed that increasing of $\mathrm{H} / \mathrm{D}$ lead to an increase in $\mathrm{C}_{\mathrm{P}}$. The power 
increase is further dependent on the brim height of the diffuser, the highest power increase was observed for multi-rotor system with an H/D of 0.1 introduced by U. Göltenbott et al [50].

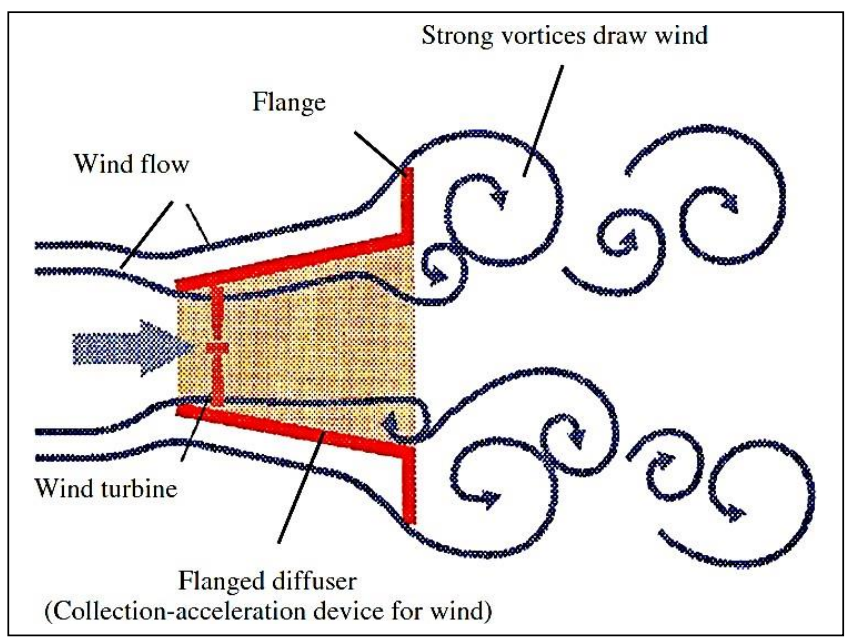

Fig. 33 Schematic view of flow mechanism around a flanged diffuser [50].

A different flange highs (h/D) in range of (0 (no flange), 0.075, 0.125, 0.25, 0.375, 0.5 and 0.625$)$ have been examined in wind tunnel by Y. Ohya et al [64] to obtain a higher wind speed at diffuser inlet which has a diameter $(\mathrm{D}=20$ $\mathrm{cm}), \mathrm{L} / \mathrm{D}=1.5$ and $\mathrm{Ae} / \mathrm{Ai}=1.44$. the effective $\mathrm{h} / \mathrm{D}=0.25$ was for accelerated of wind where the higher of this, as in Fig. 34 , provide smoothly flowing for wind due to the big rise of upstream pressure in front of the diffuser.

Numerical simulations and PIV visualizations which have been done by A. Tourlidakis et al[64] on flanged diffuser $(\mathrm{L} / \mathrm{D}=1.76, \Theta=12)$ showed that when added a flange at the diffuser outlet in range of flange height to inlet section diffuser diameter (H/D) $(0-0.6)$, two contra-turning vortices were made at this area and they move far from each other in the direction of flow with the flange height increment and they appear to lengthen in the direction of stream wise course and to stretch out in the two directions when the height of flange become taller.

Additionally, the diffuser without flange increase wind velocity about $58 \%$ while the increase in wind velocity ranged $64-81 \%$ for diffuser within flange with a critical ratio $(\mathrm{H} / \mathrm{D}=0.1)$ [68],[70]. In other words, a strong recirculation region behind the diffuser produced due to the flange where this region with high flange and causes reduction in pressure leads to more mass wind flow hence increase turbine output power.

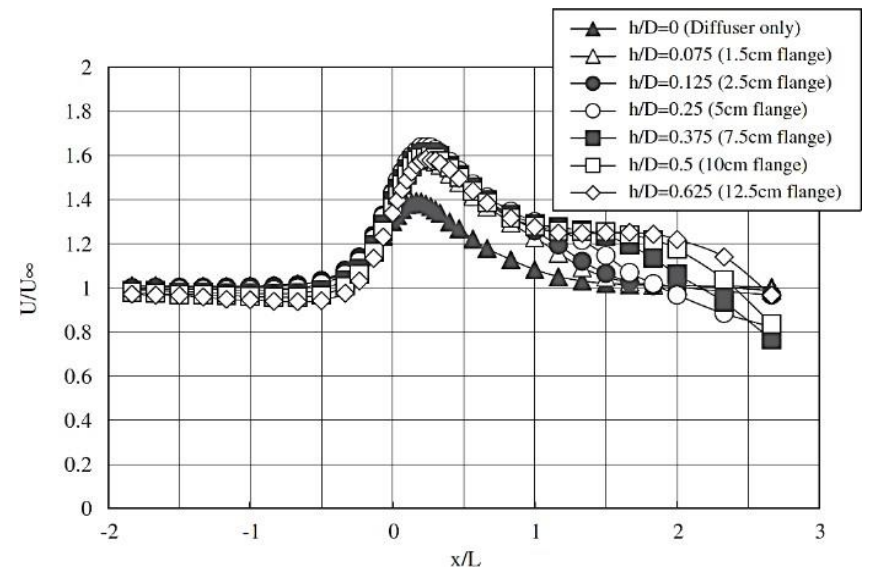

Fig. 34 Wind velocity distributions on the central axis of a circular-diffuser model with and without a flange [64].

Three different values of h/D (0.1, 0.2 and 0.3$)$ have been investigated at different diffuser angles in a range of (0$30^{\circ}$ ) by M. Lipian et al as shown in Fig. 32 [98], observed that optimum U/U $\mathrm{U}_{\infty}$ at high $\mathrm{h} / \mathrm{D}$ within relatively small diffuser angles. The typical features of the considered flow as in Fig. 35 which show velocity contour plot of flow through DAWT at $\mathrm{h} / \mathrm{D}=0.3$ and $2 \theta=8^{\circ}$. 


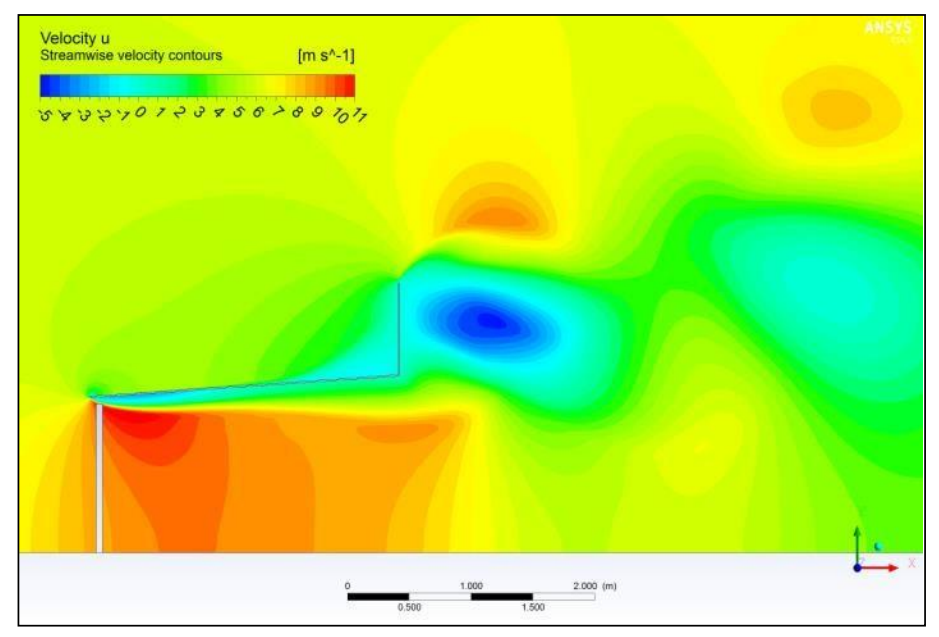

Fig. 35 Velocity contour plot of flow through DAWT [98].

Experimental and numerical results of tests which have been carried out by R. Chaker et al [69] revealed that wind speed increases at diffuser inlet with increasing of flange height. The diffuser was in $\mathrm{L} / \mathrm{D}=1.69$ and $\Theta=6.8$ where the tests have been carried out in a different range of H/D (5- 49\%). However, there is a value called an optimum for flange height expressed by the ratio of flange height to inlet diffuser diameter (H/D), optimum (H/D) of 0.15 beyond that, the effect of flange height less on the velocity increase. This behavior can be explained by both locations of two contrarotating vortices which generated downstream of the diffuser and the pressure coefficient at their centers. Indeed, it was found that, as the flange height increases, the two vortices move away from each other in the flow direction and since the flange height exceeds $\left(\mathrm{H}_{\mathrm{opt}} / \mathrm{D}\right)$, they became too distant from each other and from the flange (Fig. 36). While the pressure coefficients at the vortices' centers increase with $(\mathrm{H} / \mathrm{D})$, attain a maximum when $\left(\mathrm{H}_{\mathrm{op}} / \mathrm{D}\right)$ is reached, and then decreases. In other hand, the value of pressure coefficient depends on vortices locations which are in turn controlled by flange height. Where maximum pressure coefficient satisfy at suggested optimal ratio (H/D $)$ (about 15 to $20 \%$ ) for diffuser with inlet shroud at same $\left(L / D_{t}=1.75, \Theta=12^{\circ}\right)$ was investigated experimentally in range $H / D_{t}(0-0.5)$ by M. Kardous et al [76]. The separation behind the brim causes high wind concentration, which increases with a higher brim. On the other hand, separation inside diffuser leads to decrease turbine power, where diffuser -separation affected by the distribution of spanwise blade loading [93].
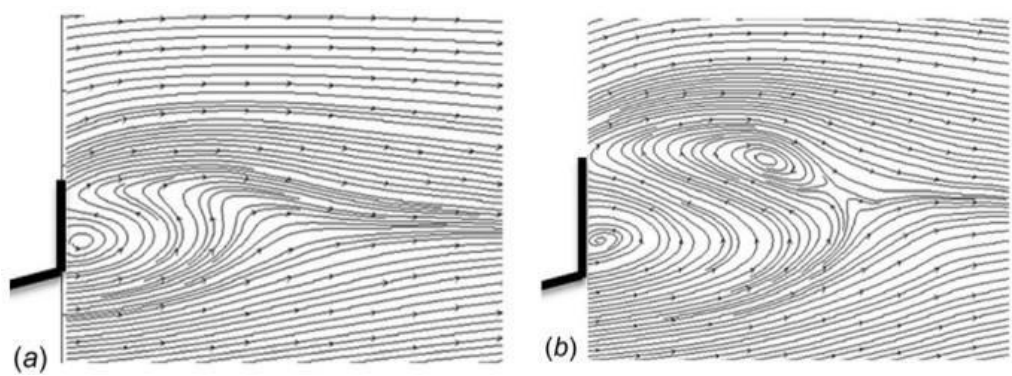

Fig. 36 Streamlines for some flange height (PIV measurement), (a) H/D=0.05 and (b) H/D=0.2 [74].

Two arrangements with Gurney Flaps (GF) statutes equivalent to $2 \%$ and $4 \%$ of the diffuser chord length $(\mathrm{cl})$ were considered by V. V. Dighe et al [92], results demonstrate that partition actuated by GF makes a low-pressure area at the exit of the diffuser where the different pressure without GF, with (GF at $2 \% \mathrm{cl}$ ) and with (GF at $4 \% \mathrm{cl}$ ) were $0.44,0.49$ and 0.51 respectively. These values of pressure difference augments the mass flow through the diffuser and the power coefficient of the DAWT where $\mathrm{C}_{\mathrm{P}}$ without GF was 0.639 while, with (GF at $2 \% \mathrm{cl}$ ) and with (GF at $4 \% \mathrm{cl}$ ) have been increased by $9.7 \%$ and $16 \%$ respectively. The wind tunnel of experimental results that conducted on HAWT with and without flange diffuser by T. Y. Chen et al [100] showed, that an increase of wind turbine power depending on wind speed and rotor solidity, where if higher solidity and wind speed are, be a smaller effect of the flanged diffuser. The simulation that performed by K. Mansour and P. Meskinkhoda [94] for wind turbine equipped with flanged and inlet diffuser shroud with diffuser open angle $4^{\circ}$ and $\mathrm{L} / \mathrm{D}$ of 1.5 at different $(\mathrm{H} / \mathrm{D})$ range $(0,0.125,0.25,0.5)$.They have observed increase in wind speed of 1.6-2.1 times of the approaching wind, therefore the power augmentation for the given turbine about four compared to bare wind turbine. 
A $3 \mathrm{kw}$ downwind-type wind turbine with a rotor diameter of $2.5 \mathrm{~m}$ generated 2.5 times more power with a compact Wind-Lens (brimmed diffuser) than the same turbine without a Wind-Lens in the field experiment, as shown in Fig. 37 [71]. For the same turbine, the rotational speed of the rotor blade of wind turbine with a flanged diffuser was about 1.35 times compared without the flanged diffuser [101].

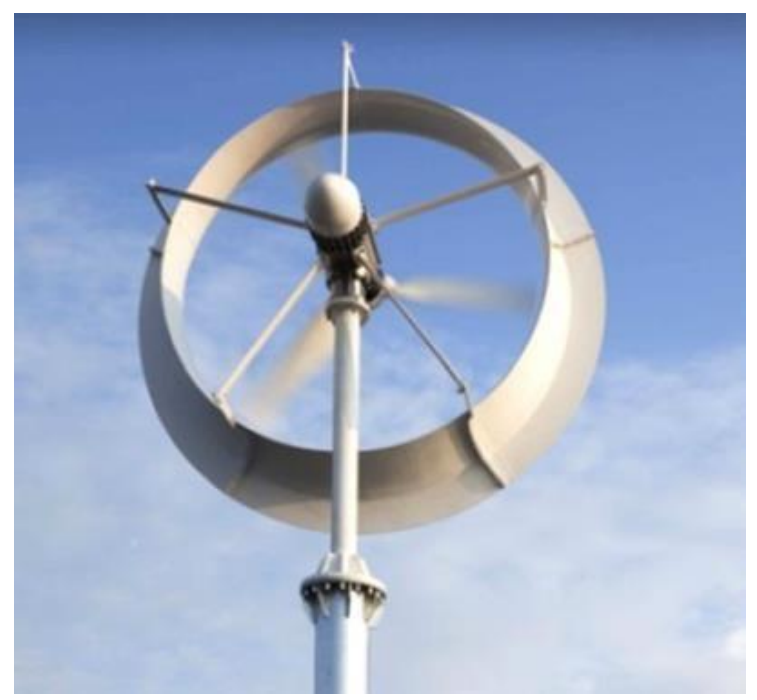

Fig. 37 Compact Wind-Lens turbine [71].

In addition of the mention above, the wind lens ( flanged diffuser) significant of a reduction in wind turbine noise and improved safety where wind turbine, rotating at a high speed, is shrouded by a structure and is also safe against damage from broken blades. Also flanged diffuser useful for Birds, where stand on the flange edge for rest. As for demerits, wind load to a wind turbine and structural weight are increased compared to the conventional turbines with the same rotor diameter [99], [101],[102]. The mechanism of the Wind Lens can be applied in the water also. Development of shrouded water turbine is ongoing at Kyushu University. A water channel experiment with small Water lens turbine demonstrated maximum power coefficient of the shrouded turbine reaches 2.5 times that of the bare turbine. Using the same diffuser design used in the Wind lens turbine [103]. To maintain the flanged diffuser from high load due to high wind speeds, a self-adaptive flange has been proposed by J. F. Hu and W. X. Wang [102] where the numerical results showed a reducing in wind load on diffuser by about $35 \%$ compared with the same diffuser at same wind conditions.

\section{Discussion}

In this paper, an extensive review of previous studies has been presented by researchers in the field of wind energy. In which the literature on aerodynamic power augmentation of the horizontal axis wind turbine was reviewed. The contributions published in improving turbine power were reviewed in two groups, the first was relating to the improvement of energy by improving the aerodynamic forces affecting on HAWT in different modifications for blades. While the second one reviewed different techniques to augment largest possible amount of power from HAWT focusing on augmentation duct concept DAWT. Therefore, review on different designs of diffuser augmented wind turbine from previous studies included numerical and experimental procedures. In addition, it has been presented an exhaustive review of these contributions in terms of shape design and mechanisms investigation of as summarized in Table 2 . The effects of important parameters which included diffuser length and open angle of diffuser are shown in table 3 , while, Table 4 summarizes the effect of brim (flange) height as on DAWT performance. From this study, it is concluded that there is a consensus among scientists in recent researches of that the Diffuser Augmented Wind Turbine exhibits the best advantages compared to other augmentation solutions in the production of power at high performance exceeding the Betz limit. This increase in energy was explained through augmenting the upstream wind velocity by placing the turbine at the inlet of the diffuser with small clearance distance between diffuser wall and blade tips. The Diffuser Augmented Wind Turbine concept can be used for micro and small wind turbine at the wide and urban areas for producing the electricity. Where it is not required a high elevation, so DAWT is very effective if it designed with a suitable shape model of diffuser at optimum values for ratio of exit to inlet area and open angle. Additionally, the flange diffuser gives higher performance compared with un-flanged diffuser due to production of vortices behind the flange which causes an increase of pressure difference at downstream hence more mass flow pass through the rotor plane. The benefits of placing the flange at the outlet of the diffuser not only improves the wind mass flow rate but, it is useful in tracking the flow direction if the turbine is equipped with the yaw system.

Table 2 Literature Review Summary for the shape design and Mechanisms investigation of DAWT 


\begin{tabular}{|c|c|c|c|c|c|c|}
\hline Author & Year & $\begin{array}{l}\text { Research } \\
\text { method }\end{array}$ & Technique/features & $\overline{A_{e} / \mathbf{A}_{\mathbf{i}}}$ & $\begin{array}{l}\text { Total-L } \\
(\mathbf{m})\end{array}$ & $\begin{array}{c}\text { Comments/ Results } \\
\text { (At wind speed range test }(\mathrm{m} / \mathrm{s}) \text { ) } \\
\end{array}$ \\
\hline M.Sanuki & 1950 & $\mathrm{E}$ & Ventilator tube (C-D) & 1.29 & 1.21 & $(+)$ Cp by $4 \%,(-)$ \\
\hline M.Iwasaki & 1953 & $\mathrm{~T}, \mathrm{E}$ & Circular ring & 1 & - & $(+)$ power up to $30 \%,(-)$ \\
\hline G.M.Lilly & 1956 & $\mathrm{~T}$ & Simple shroud & 3.5 & - & $(+)$ power up to $65 \%,(-)$ \\
\hline A.Kogan & 1963 & $\mathrm{E}$ & $\begin{array}{l}\text { Bell shape shroud }(\mathrm{C}- \\
\text { D) }\end{array}$ & 3.5 & $6.82 \mathrm{D}$ & $(+)$ power $3-3.5,(-)$ \\
\hline O.Igra & 1976 & $\mathrm{E}$ & Annular wing shroud & 4.37 & 2.27D & $(+)$ power factor $1.69, \underline{(-)}$ \\
\hline O.Igra & 1976 & $\mathrm{E}$ & $\begin{array}{l}\text { Annular wing shroud } \\
\text { with exit flap }\end{array}$ & 8.33 & 3.07D & $(+)$ power factor $2.26, \underline{(-)}$ \\
\hline K.Foreman & 1981 & $\mathrm{~T}$ & Compact diffuser & 2.75 & - & $\begin{array}{l}(+)(\mathrm{P}) \text { with area ratio },\left(\mathrm{V}_{\text {avarge }}=7.14\right. \\
\mathrm{m} / \mathrm{s} \text { range of }(2.67-17.78) \mathrm{m} / \mathrm{s}\end{array}$ \\
\hline O. Igra & 1984 & $\mathrm{E}$ & Simple diffuser & 4 & $2.67 \mathrm{D}$ & $(+) \mathrm{C}_{\mathrm{P}}$ to $1.4, \underline{(-)}$ \\
\hline AlSulaimn & 2015 & $\mathrm{~T}$ & Simple Duct & $\begin{array}{l}1.1 \\
1.3 \\
\text { and } \\
1.5\end{array}$ & - & $\begin{array}{l}(+) \text { area ratio }(+) \text { power, }(\underline{V} \text { range of } \\
\underline{(6-13) \mathrm{m} / \mathrm{s}}\end{array}$ \\
\hline AlSulaimn & 2017 & $\mathrm{~T}$ & Ejector & $\begin{array}{c}\mathrm{r}_{\mathrm{s}} \\
(0.8, \\
1, \text { and } \\
1.2)\end{array}$ & - & $\begin{array}{l}(+) \text { area ratio }(+) \text { power, }(\underline{V} \text { range of }(5- \\
\underline{15) \mathrm{m} / \mathrm{s}}\end{array}$ \\
\hline M.J. Werle & 2008 & $\mathrm{~T}$ & Simple duct & $1,1.3$ & - & $(+)$ area ratio and $L(+) C_{P}(-)$ \\
\hline R.F.Ghajar & 2012 & $\mathrm{E}$ & $\begin{array}{l}\text { Diffuser } \\
\text { Collector-Diffuser }\end{array}$ & $\begin{array}{l}1.67 \\
1.19\end{array}$ & $\begin{array}{l}0.289 \\
0.408\end{array}$ & $\begin{array}{l}\text { CDAWT }(+) \text { power by } 56 \% \text { over } \\
\text { DAWT and reach } 4 \text { times over bare } \\
\text { turbine power, }(\underline{V} \text { of }(12.3 \text { and } \\
\underline{16.6) \mathrm{m} / \mathrm{s}}\end{array}$ \\
\hline B. Kosasih & 2012 & $\mathrm{E}$ & $\begin{array}{l}\text { a. Primed Diffuser } \\
\text { b. Nozzle-Diffuser }\end{array}$ & 1.61 & 0.12 & $\begin{array}{l}\text { a. Enhance }\left(C_{P}\right) \text { up to } 60 \% . \\
\text { b. Enhance }\left(C_{P}\right) \text { up to } 63 \% . \\
(V \text { of }(5-10) \mathrm{m} / \mathrm{s},(\lambda \text { of } 0.5-3.5)\end{array}$ \\
\hline S.H. Wang & 2008 & S & $\begin{array}{l}\text { (+)blades no. }(2,4,6 \\
\text { and } 8) \text { to C-D Nozzle }\end{array}$ & 1.33 & 1 & (-) $C_{P},(V=12 \mathrm{~m} / \mathrm{s}),(\lambda$ of $0-10)$ \\
\hline H. Ahmadi & 2017 & $\mathrm{E}$ & $\begin{array}{l}\text { Changing design } \\
(\mathrm{WB}),(\mathrm{CW}) \text { and } \\
(\mathrm{WP}) \text {. and blades } \\
\text { number }(2,3 \text { and } 4)\end{array}$ & 1.2 & 2.4 & $\begin{array}{l}(-)(\omega) \text { by } 10 \%-12.5 \% \text { for each blade } \\
\text { added with increase in torques. (WP) } \\
\text { blades have lower }(\omega) \text { Max. }(\omega) \text { at } 75 \\
\text { attack angle within duct, }(\mathrm{V}=3.18 \mathrm{~m} / \mathrm{s})\end{array}$ \\
\hline K. Olasek & 2016 & $\mathrm{E}$ & $\begin{array}{l}3 \text { models of different } \\
\text { sizes of DAWT }\end{array}$ & 1.07 & 0.54 & $\begin{array}{l}\text { D30 very good (best) for investigation, } \\
(+)\left(C_{\mathrm{P}}\right) \text { by } 70-75 \text { with using } \mathrm{D} 30,(\mathrm{~V} \\
\text { of } 6,8,10,12,16 \mathrm{~m} / \mathrm{s})\end{array}$ \\
\hline U.Göltenbott & 2017 & $\mathrm{E}$ & $\begin{array}{l}\text { Brimmed Multi-rotor } \\
\text { systems (MRS) of } \\
\text { DAWT }\end{array}$ & - & 0.07 & $\begin{array}{l}(+) 5 \% \text { for } 2 \text { rotor at } s / D=0.5,(+) 9 \% \\
\text { for } 3 \text { rotor at } s / D=0.15 \text {, brim height of } \\
10 \% D_{\text {throat }},(V=7 \mathrm{~m} / \mathrm{s}),(\lambda \text { of } 3-5) \text {. }\end{array}$ \\
\hline T.S.Kannan & 2013 & S & 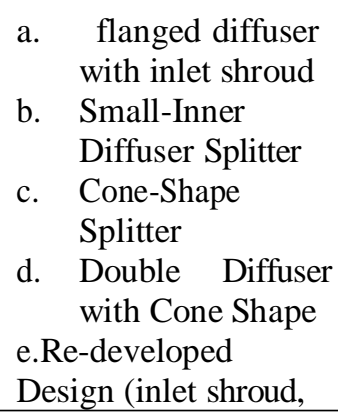 & - & $\begin{array}{l}1(\mathrm{~d}) \\
0.5(\mathrm{id}\end{array}$ & $\begin{array}{l}\Theta \text { : diffuser opining angle }, \Theta_{1} \text { : con or } \\
\text { splitter opining angle } \\
\text { a. upstream wind velocity }\left(\mathrm{U}_{\infty}\right) \\
67.12 \% \text { at } \Theta \text { of } 12^{\circ} \\
\text { b. }\left(\mathrm{U}_{\infty}\right)(+) 35.25 \% \text { at } \Theta=8^{\circ}, \Theta_{1}=8^{\circ} \\
\text { c. }\left(\mathrm{U}_{\infty}\right)(+) 23.25 \% \text { at } \Theta=8^{\circ}, \Theta_{1}=8^{\circ} \\
\text { d. }\left(\mathrm{U}_{\infty}\right)(+) 6.18 \text { at } \Theta=16^{\circ}, \Theta_{1}=16^{\circ} \\
\text { e. }\left(\mathrm{U}_{\infty}\right)(+) 61.25 \% \text { at } \Theta=16, \Theta_{1}=4^{\circ} \\
\left(\mathrm{V}_{\text {ave }}=4 \mathrm{~m} / \mathrm{s}\right)\end{array}$ \\
\hline
\end{tabular}




\begin{tabular}{|c|c|c|c|c|c|c|}
\hline \multicolumn{6}{|c|}{ flange and splitter into } & \multirow[b]{2}{*}{$\begin{array}{c}\text { Comments/ Results } \\
\text { (At wind speed range test }(\mathrm{m} / \mathrm{s}) \text { ) }\end{array}$} \\
\hline Author & Year & $\begin{array}{l}\text { Research } \\
\text { method }\end{array}$ & Technique/features & $\mathbf{A} \mathbf{A}_{\mathbf{A}} \mathbf{A}_{\mathbf{i}}$ & $\begin{array}{l}\text { Total- } \\
\text { L }(\mathbf{m})\end{array}$ & \\
\hline S. Hjort & 2014 & $\mathrm{~S}$ & Muli-element diffuser & - & $x$ & $(+)(\mathrm{P})$ up to $50 \%(-)$ \\
\hline $\begin{array}{l}\text { M.A. } \\
\text { Arabbeiki }\end{array}$ & 2016 & & $\begin{array}{l}\text { balloon as shape of C-D } \\
\text { Nozzle }\end{array}$ & 0.88 & $0.8 \mathrm{Dt}$ & $\begin{array}{l}(+)\left(\mathrm{U}_{\infty}\right) \text { up to } 1.33-1.66, \underline{\mathrm{V} \text { of }(6} \\
\text { and } 12) \mathrm{m} / \mathrm{s} .\end{array}$ \\
\hline B. Ahmed & 2016 & $S$ & flanged diffuser & 2 & 0.12 & $\begin{array}{l}(+)\left(\mathrm{U}_{\infty}\right) \text { up to } 125.666 \%,\left(\underline{\mathrm{V}_{\text {ave }}=}\right. \\
\underline{\mathrm{m} / \mathrm{s}})(+) \text { Power } 1.6-1.7 \text { times }\end{array}$ \\
\hline S. Z. Roshan & 2015 & S & Stepped duct & 1.2 & 0.755 & $\begin{array}{l}(+)\left(C_{P}\right) \text { by } 16 \% \text { when locate the step } \\
\text { at outlet of duct, }(\mathrm{V}=5 \mathrm{~m} / \mathrm{s}),(\lambda \text { of } 0- \\
\text { 3.5) }\end{array}$ \\
\hline A. Lotfi & 2012 & $S$ & $\begin{array}{l}\text { tubular divergent- } \\
\text { truncated cone }\end{array}$ & 2.4 & 0.171 & $\begin{array}{l}\text { (+) }\left(\mathrm{U}_{\infty}\right) \text { by } 60 \% \text { for primary model } \\
\text { (T) }\left(\text { range of } \operatorname{Re} 4.7 * 10^{4}-1.88 * 10^{7}\right)\end{array}$ \\
\hline A.C.Aranake & 2015 & S & $\begin{array}{l}\text { diffuser with High-lift } \\
\text { airfoil section }\end{array}$ & - & - & $\begin{array}{l}\text { (+) (P) up to } 1.93 \text { times, }(\mathrm{V} \text { of }(3- \\
\underline{25) \mathrm{m} / \mathrm{s}}\end{array}$ \\
\hline D.P.Georgiou & 2012 & $S$ & ejector assisted diffuser & - & - & $(+)\left(C_{P}\right)$ up to $0.6,\left(\mathrm{~V}_{\text {ave }}=12 \mathrm{~m} / \mathrm{s}\right)$ \\
\hline J. Wang & 2013 & S & $\begin{array}{l}\text { ducted multi-blade } \\
\text { composite wind turbine }\end{array}$ & - & - & $\begin{array}{l}(+)(\mathrm{P}) \text { by } 2-3 \text { times of bare turbine } \\
,(\mathrm{V} \text { of }(3-15) \mathrm{m} / \mathrm{s}\end{array}$ \\
\hline N. Oka & 2016 & $S$ & Optimum wind-lens & - & - & $(+)\left(\mathrm{C}_{\mathrm{P}}\right)$ up to $0.604,\left(\mathrm{~V}_{\mathrm{ave}}=10 \mathrm{~m} / \mathrm{s}\right)$ \\
\hline H.M.Elbakry & 2016 & $S$ & $\begin{array}{l}\text { (diffuser splitter with } \\
\left(\Theta_{s}\right) \text { in flanged diffuser } \\
\text { with }(\Theta)\end{array}$ & - & - & $\begin{array}{l}(+)(\text { mass flow }),(+)\left(C_{\mathrm{P}}\right) \text { at } \Theta_{\mathrm{s}}<\Theta \\
\left(\mathrm{V} \text { rang of } 5-15 \mathrm{~m} / \mathrm{s}, \mathrm{V}_{\text {ave }}=10 \mathrm{~m} / \mathrm{s}\right) \\
(\lambda \text { of } 1-9)\end{array}$ \\
\hline A. Nasution & 2011 & S & $\begin{array}{l}\text { diffuser NACA } 5807 \\
\text { airfoil section }\end{array}$ & 1.01 & 0.2 & $\begin{array}{l}(+)\left(\mathrm{U}_{\infty}\right) \text { by } 65.5 \% \text { of bare turbine } \\
(-)\end{array}$ \\
\hline A.Tourlidakis & 2013 & S & $\begin{array}{l}\text { Diffuser } \\
\text { within flange }\end{array}$ & 1.65 & 4.8 & $\begin{array}{l}(+)\left(C_{P}\right) \text { up to } 2-5 \text { times of bare } \\
\text { turbine, } \underline{\left.V_{\text {ave }}=5 \mathrm{~m} / \mathrm{s}\right)} \\
(\lambda \text { of } 3.2-7.7)\end{array}$ \\
\hline C. Chaudhari & 2013 & $S$ & Venturi Duct & 1.5 & 2.3 & $\begin{array}{l}\text { (+) }\left(\mathrm{U}_{\infty}\right) \text { by } 1.75 \text { times }(60 \%) \\
(+)(\mathrm{P}) 5 \text { times, }\left(\mathrm{V}_{\text {ave }}=10 \mathrm{~m} / \mathrm{s}\right)\end{array}$ \\
\hline K.Mansour & 2014 & S & $\begin{array}{l}\text { flanged and } \\
\text { diffuser shroud }\end{array}$ & 1.2 & 0.2 & $\begin{array}{l}(+)\left(\mathrm{U}_{\infty}\right) 1.6-2.1 \text { times } \\
\left(\mathrm{V}_{\mathrm{ave}}=5 \mathrm{~m} / \mathrm{s}\right)\end{array}$ \\
\hline
\end{tabular}

NOTE: $(\mathrm{E})$ experimental, $(\mathrm{T})$ theoretical, $(\mathrm{S})$ simulation, $(+)$ mean increase, $(-)$ decrease, $(\mathrm{P})$ : Power, $\left(\mathrm{C}_{\mathrm{P}}\right)$ : Power Coefficient, $(\mathrm{U} \infty)$ : upstream wind speed, $(\Delta \mathrm{p})$ : pressure difference, $(\omega)$ : Rotational speed, $\left(\mathrm{V}_{\text {ave }}\right)$ : average wind velocity used in test. 
Table 3 Literature Review Summary for the effect of diffuser length and angle of diffuser on power augmentation of DAWT

\begin{tabular}{|c|c|c|c|c|}
\hline Author & Year & $\begin{array}{l}\text { Research } \\
\text { method }\end{array}$ & Range of $L, \theta$ & $\begin{array}{c}\text { Comments/ Results } \\
\text { (At wind speed range test }(\mathrm{m} / \mathrm{s}) \text { ) }\end{array}$ \\
\hline B.Kosasih & 2012 & $\mathrm{E}$ & $\begin{array}{l}\mathrm{L}(0.36-1.47) \mathrm{D}_{\mathrm{r}} \text { at same } \\
\Theta\end{array}$ & $\begin{array}{l}(+) \mathrm{L} / \mathrm{D}_{\mathrm{r}} \text { led to }(+) \mathrm{TSR},(-) \text { cut-in-speed, }(\mathrm{V} \text { of }(5-10) \mathrm{m} / \mathrm{s} \\
(\lambda \text { of } 0.5-3.5)\end{array}$ \\
\hline R.Kishore & 2013 & S & $\begin{array}{l}\text { L2 }(0.5-1.5) \mathrm{Dt} \\
\mathrm{L} 1(0.125-0.5) \mathrm{Dt} \\
\Theta 1, \Theta 2 \text { in }\left(0-16^{\circ}\right)\end{array}$ & $\begin{array}{l}\text { (+) } \mathrm{U} / \mathrm{U}_{\infty} \text { up to } 1.2 \text { and }(+) \text { power }(1.4-1.6) \text { times, at } \mathrm{L}_{2}=\mathrm{D}_{\mathrm{t}} \text {, } \\
\Theta_{2}=10, \mathrm{~L}_{1}=0.125 \mathrm{D}_{\mathrm{t}}, \Theta_{1}=15,(\mathrm{~V} \text { of }(1.8-5) \mathrm{m} / \mathrm{s},(\lambda \text { of } 0-5)\end{array}$ \\
\hline M.Kardous & 2016 & $\mathrm{E}, \mathrm{S}$ & $\begin{array}{l}\mathrm{L}(0.25-3.25) \mathrm{D}_{\mathrm{r}} \\
\Theta\left(0-30^{\circ}\right)\end{array}$ & $\begin{array}{l}\text { (+) } \mathrm{U} / \mathrm{U}_{\infty} \text { up to } 1.68 \text { at } \mathrm{L}=1.5 \mathrm{Dr}, \Theta=10^{\circ} \text { for diffuser. }(+) \\
\mathrm{U} / \mathrm{U}_{\infty} \text { up to } 1.47 \mathrm{Dr}, \Theta=12^{\circ}(\mathrm{DAWT}),\left(\mathrm{V}_{\mathrm{ave}}=5 \mathrm{~m} / \mathrm{s}\right)\end{array}$ \\
\hline S.A. Jafari & 2014 & S & $\begin{array}{l}\mathrm{L}(0.1-0.4) \mathrm{D} \\
\mathrm{Do}(1.051 .7) \mathrm{D}\end{array}$ & $\begin{array}{l}(+) \mathrm{L} / \mathrm{D} \text { led to }(+) \text { power at optimum } \mathrm{Do}(1.1-1.3) \\
\left(\underline{\left.\mathrm{V}_{\mathrm{ave}}=6 \mathrm{~m} / \mathrm{s}\right),(\lambda \text { of } 0-5)}\right.\end{array}$ \\
\hline T.S.Kannan & 2013 & S & $\begin{array}{l}\Theta \quad \text { Os }(4-16) \text { for } \\
\text { concepts (a,b,c,d and } \\
\text { redeveloped-(e)) } \\
\text { (fig.2.14) }\end{array}$ & $\begin{array}{l}\text { a. }(+)\left(\mathrm{U}_{\infty}\right) \text { by } 67.12 \% \text { at } \Theta=12,\left(\mathrm{~V}_{\mathrm{ave}}=4 \mathrm{~m} / \mathrm{s}\right) \\
\text { b. }(+)\left(\mathrm{U}_{\infty}\right) \text { by } 35.25 \% \text { at } \Theta=8, \Theta \mathrm{s}=8 \\
\text { c. }(+)\left(\mathrm{U}_{\infty}\right) \text { by } 23.25 \% \text { at } \Theta=8, \Theta \mathrm{s}=8 \\
\text { d. }(+)\left(\mathrm{U}_{\infty}\right) \text { by } 54.5 \% \text { at } \Theta=16, \Theta \mathrm{s}=16 \\
\text { e. }(+)\left(\mathrm{U}_{\infty}\right) \text { by } 61.25 \% \text { at } \Theta=16, \Theta \mathrm{s}=4 \text {, }\end{array}$ \\
\hline R. Chaker & 2013 & S & $\Theta(0-35)$ & $\begin{array}{l}(+) \Theta \text { led to }(+) \mathrm{U} / \mathrm{U}_{\infty},\left(\mathrm{V}_{\mathrm{ave}}=5 \mathrm{~m} / \mathrm{s}\right) \\
\mathrm{U} / \mathrm{U}_{\infty}=1.76 \text { at } \Theta_{\text {optimum }}=10(\text { diffuser }) \\
\mathrm{U} / \mathrm{U}_{\infty}=1.45 \text { at } \Theta_{\text {optimum }}=12(\mathrm{DAWT})\end{array}$ \\
\hline H.Elbakry & 2016 & S & $\begin{array}{l}\text { 1.Splitter with }(\Theta s) \\
\text { inside diffuser with }(\Theta) \text {. } \\
\text { 2. Splitter with }(\Theta s) \\
\text { inside flange diffuser } \\
\text { with }(\Theta) . \mathrm{L}(0.15-0.4) \mathrm{Dr}\end{array}$ & $\begin{array}{l}\text { 1.(-) diffuser effect, }(-) \text { mass flow, } \\
(-) C_{P}(\text { at } \Theta s>\Theta) \text {. } \\
\text { 2.(+) diffuser effect, }(+) \text { mass flow, }(+) C p(\text { at } \Theta s<\Theta) \text {. } \\
\left(\text { V rang of } 5-15 \mathrm{~m} / \mathrm{s}, V_{\mathrm{ave}}=10 \mathrm{~m} / \mathrm{s}\right)(\lambda \text { of } 1-9)\end{array}$ \\
\hline M. Lipian & 2015 & S & $\begin{array}{l}2 \Theta(0-30) \\
\mathrm{H}(0.1,0.3,0.5) \mathrm{D}\end{array}$ & $\begin{array}{l}\text { Accepted }(+) \mathrm{U} / \mathrm{U}_{\infty} \text { at } 2 \Theta \text { range }(18-26), \max . \mathrm{U} / \mathrm{U}_{\infty}=1.6 \text { at } \\
2 \Theta=6 .\left(\mathrm{V}_{\mathrm{ave}}=6 \mathrm{~m} / \mathrm{s}\right)\end{array}$ \\
\hline
\end{tabular}

Table 4 Literature Review Summary for the effect of brim (flange) on power augmentation of DAWT

\begin{tabular}{|c|c|c|c|c|}
\hline Author & Year & $\begin{array}{l}\text { Research } \\
\text { method }\end{array}$ & $\begin{array}{c}\text { Range of Brim Height } \\
(\mathbf{H})\end{array}$ & 1 \\
\hline B. Kosasih & 2012 & $\mathrm{E}$ & $\begin{array}{l}\mathrm{H}(0,0.15,0.2) \mathrm{D}_{\mathrm{r}} \text { at same } \\
\left(\mathrm{L} / \mathrm{Dr}=0.63, \quad \Theta=12^{\circ}\right)\end{array}$ & $\begin{array}{l}\text { (+) } \mathrm{H} / \mathrm{Dr} 1 \\
(\mathrm{DAWT}),(\end{array}$ \\
\hline Y. Ohya & 2008 & $\mathrm{E}$ & $\begin{array}{l}\mathrm{H}(0,0.075,0.125,0.25, \\
0.375,0.5,0.625) \mathrm{D}, \quad \mathrm{L} / \mathrm{D} \\
=1.5 \text {, aria ratio } \mathrm{A}_{\mathrm{r}}=1.44\end{array}$ & $\begin{array}{l}(+) \mathrm{H} / \mathrm{D} \text { le } \\
0.25,\left(\mathrm{~V}_{\mathrm{ave}}=\right.\end{array}$ \\
\hline M.Kardous & 2013 & $\mathrm{~S}, \mathrm{E}$ & $\begin{array}{l}\text { No flange }(H / D)=0 \text { and } \\
H(0.1-0.6) D \text {, at same } \\
(L / D=1.76, \Theta=12)\end{array}$ & $\begin{array}{l}\left(\mathrm{U}_{\infty}\right)(+) \text { by } \\
\left(\mathrm{U}_{\infty}\right)(+)(64 \\
\left(\mathrm{V}_{\mathrm{ave}}=5 \mathrm{~m} / \mathrm{s}\right)\end{array}$ \\
\hline M.Lipian & 2015 & S & $\begin{array}{l}\mathrm{H}(0.1,0.3,0.5) \mathrm{D} \\
\Theta(0-30)\end{array}$ & $\begin{array}{l}\text { Max (+) U/ } \\
\text { Small H mu }\end{array}$ \\
\hline R. Chaker & 2016 & $\mathrm{E}$ & $\begin{array}{l}\mathrm{H}(5-49 \%) \mathrm{D} \text { at same } \\
(\mathrm{L} / \mathrm{D}=1.69, \Theta=6.8)\end{array}$ & $\begin{array}{l}(+) \mathrm{U} / \mathrm{U}_{\infty} \mathrm{u} \\
\text { trivial effec }\end{array}$ \\
\hline M.Kardous & 2016 & $\mathrm{E}, \mathrm{S}$ & $\begin{array}{l}\mathrm{H}(0-0.5) \mathrm{Dt} \text { at same } \\
(\mathrm{L} / \mathrm{Dt}=1.75, \quad \Theta=12)\end{array}$ & $\begin{array}{l}\text { Max pressuı } \\
\max \mathrm{U} / \mathrm{U}_{\infty}\end{array}$ \\
\hline V.V.Dighe & 2017 & S & $\begin{array}{l}2 \text { Gurney Flab (GF) } \mathrm{H} \text { (no } \\
\text { GF, } 2 \%, 4 \% \text { of chord } \\
\text { length. } \\
\text { DAWT, (Actuator Disk) }\end{array}$ & $\begin{array}{l}(\Delta \mathrm{p})=0.44 \\
(\Delta \mathrm{p})=0.49 \\
(\Delta \mathrm{p})=0.51 \\
\text { and } 10 \mathrm{~m} / \mathrm{s})\end{array}$ \\
\hline K.Mansour & 2014 & S & $\begin{array}{l}\mathrm{H}(0,0.125,0.25,0.5) \mathrm{D} \\
\text { at same }(\mathrm{L} / \mathrm{D}=1.5, \quad \mathrm{O}=4) \\
\text { DAWT (Actuator Disk) }\end{array}$ & $\begin{array}{l}(+)\left(\mathrm{U}_{\infty}\right) \text { up } \\
(+) \text { power }(\end{array}$ \\
\hline
\end{tabular}




\section{Conclusion}

For continue to seek concepts of developing utilization of wind energy especially at low wind speeds areas, this work give guideline to provide useful knowledge for power augmentation of HAWT by DAWT technology for researchers in their future studies.

The conclusions drawn from the present reviews indicate that the use of DAWT achieves a quantum leap in increasing the production of wind power compared with conventional wind turbines especially for small turbines in urban areas. As proven that enclosing HAWT in a diffuser will increase the performance significantly in terms of $U / U_{\infty}$, hence $\mathrm{C}_{\mathrm{P}}$ value. However, an optimum design is necessary to ensure that. From the present review, the prominent points are summarized below:

a. The configurations of the shroud of DAWT included the simple diffuser, diffuser with an inlet shroud, converged diverged diffuser, curved diffuser, flanged diffuser, and multilayer diffuser.

b. The limited increase of the diffuser area ratio lead to increase wind flow inside the diffuser to a certain extent, and as the area ratio is related to the length of the diffuser to satisfy the optimum shape design, so diffuser length will be an indicator for diffuser shape.

c. Increasing the area ratio beyond optimum design causes flow separation, chocking, and back pressure increment, hence reduction in wind flow speed at rotor plane. Moreover, Low area ratios can be used for moderate high wind speed in order to overcome flow separation, vice versa.

d. The material used for diffuser should be suitable for both, weight and mechanical forces criteria since the diffuser work as a container and holder for the turbine .from another hand, light and strong material must be used for blades as fiberglass reinforced plastics which can be used for the diffuser.

e. DAWT with an appropriate flange height at the outlet of the diffuser is more efficient than a DAWT without a flange, especially if it is supported by an inlet shroud. Also, the flange provides work as a free mechanism for tracking the wind direction.

f. Also DAWT is an economically viable concept to produce power from wind sources as compared with other wind machine concepts. Furthermore, the DAWT concept reduces turbine noise and protects the turbine blades against the broken.

g. optimum design for shroud will generally increase power obtain from any turbine used, but in order to reach optimum power getting from this turbine, a combination with a developed design for turbine blade is necessary.

\section{References}

[1] W. Tong.Wind Power Generation and Wind Turbine Design. (2010) WIT Press.

[2] K. H. Wong, W. T. Chong, N. L. Sukiman, S. C. Poh, Y. C. Shiah, and C. T. Wang. Performance enhancements on vertical axis wind turbines using flow augmentation systems: A review.Renew. Sustain. Energy Rev., vol. 73, (2017), pp. 904-921.

[3] M. Adnan et al. .Bedload Sediment Concentration of Sungai Kahang Downstream Kahang Dam in Johor. International Journal of Integrated Engineering, vol. 10, no. 2, (2018), pp. 146-150.

[4] D. H. Didane, A. Ab Wahab, S. S. Shamsudin, and N. Rosly. Wind as a sustainable alternative energy source in Malaysia - a review," ARPN J. Eng. Appl. Sci., vol. 11, no. 10, (2016), pp. 6442-6449.

[5] A. Raheem, M. Hassan, and R. Shakoor. Economic feasibility of stand-alone wind energy hybrid with bioenergy from anaerobic digestion for electrification of remote area of Pakistan. International Journal of Integrated Engineering, vol. 6, no. 3, (2014), pp. 1-8.

[6] X. L. Khai et al. Harvesting Electrical Energy from Rooftop Ventilator,” International Journal of Integrated Engineering., vol. 10, no. 4, (2018), pp. 68-72.

[7] A. I. Hassane, A. M. Tahir, D. H. Didane, and J.-M. Hauglustaine. Wind and Solar Assessment in the Sahelian Zone of Chad. International Journal of Integrated Engineering, vol. 10, no. 8, (2018), pp. 164-174.

[8] L. Rajendran and S. T. Thirugnana. Urban Metro Elevated Station to Generate Solar Power. International Journal of Integrated Engineering, vol. 10, no. 7, (2018), pp. 156-166.

[9] N. Aini Bani et al., "Feasibility Study of a Low Cost Saltwater Lamp for Rural Area. International Journal of Integrated Engineering, vol. 10, no. 7, (2018), pp. 167-176,

[10] M. Chandrala, A. Choubey, and B. Gupta. CFD analysis of horizontal axis wind turbine blade for optimum value of power. Int. J. Energy Environ., vol. 4, no. 5, (2013), pp. 825-834.

[11] D. H. Didane, N. Rosly, M. F. Zulkafli, and S. S. Shamsudin. Evaluation of Wind Energy Potential as a Power Generation Source in Chad. Int. J. Rotating Mach., no. ID 3121875, (2017).

[12] M. A. Arabbeiki Zefreh. Design and CFD Analysis of Airborne Wind Turbine for Boats and Ships. Int. J. Aerosp. Sci., vol. 4, no. 1, (2016), pp. 14-24.

[13] I. Emovon, O. D. Samuel, C. O. Mgbemena, and M. K. Adeyeri. Electric Power generation crisis in Nigeria : A Review of causes and solutions. International Journal of Integrated Eng.,vol. 10, no.1, (2018), pp. 47-56.

*Corresponding author: balasemalquraishi@etcn.edu.iq ; balasemalquraishi@gmail.com

2019 UTHM Publisher. All right reserved.

penerbit.uthm.edu.my/ojs/index.php/ijie 
[14] J. N. Libii and D. M. Drahozal.The influence of the lengths of turbine blades on the power produced by miniature wind turbines that operate in non-uniform flow fields. World Trans. Eng. Technol. Educ., vol. 10, no. 2, (2012), pp. $128-133$.

[15] O. Igra.Research and Development for Shrouded Wind Turbines. Energy Conv., vol. 21, (1981), pp. 13-48.

[16] D. H. Didane, N. Rosly, M. F. Zulkafli, and S. S. Shamsudin. Performance evaluation of a novel vertical axis wind turbine with coaxial contra-rotating concept. Renew. Energy, vol. 115, (2018), pp. 353-361.

[17] R. W. Y. Habash, V. Groza, Y. Yang, C. Blouin, and P. Guillemette. Performance of a Contrarotating SmallWind EnergyConverter. ISRN Mecahnical Eng., (2011), no. ID 828739.

[18] F.A. Van Dorst. An Improved Rotor Design for a Diffuser Augmented Wind Turbine," Master of Science Thesis,Eindhoven University of Technology, (2011).

[19] V. Holten and Th. .Concentrator systems for wind energy, with emphasis on tipvanes. Wind Eng., vol. 5, (1981), pp. 29-45.

[20] E. Dick. Power Limits for Wind Energy Concentrator Systems. Wind Eng., vol. 10, no. 2, (1986), pp. 98-115.

[21] V. Holten and Th. . Windmills with diffuser effect induced by small tipvanes," International Symposium on Wind Energy Systems. Cambridge, England, (1986).

[22] O. de Vries. Fluid Dynamic Aspects of Wind Energy Conversion. AGARD, (1979).

[23] J. N. Sørensen. Aerodynamic Aspects of Wind Energy Conversion," Annu. Rev. Fluid Mech., vol. 43, no. 1, (2011), pp. 427-448.

[24] S. I. Yannopoulos et al.. Evolution of water lifting devices (Pumps) over the centuries worldwide. Water (Switzerland), vol. 7, no. 9, (2015), pp. 5031-5060.

[25] C. Rica."Global Wind Statistics 2017.GWEC, (2018).

[26] S. Eriksson, H. Bernhoff, and M. Leijon. Evaluation of different turbine concepts for wind power. Renew. Sustain. Energy Rev., vol. 12, no. 5, (2008), pp. 1419-1434.

[27] C. Shonhiwa and G. Makaka. Concentrator Augmented Wind Turbines: A review. Renew. Sustain. Energy Rev., vol. 59, (2016), pp. 1415-1418.

[28] A. P. Schaffarczyk. Introduction to Wind Turbine Aerodynamics - Chapter 2. Green Energy Technol., vol. 153, (2014), pp. 7-21.

[29] J. F. Manwell and J. G. McGowan. Wind Energy Explained, Theory, Design and Application, Second Edi. Wiley \& Sons Ltd (2009).

[30] B. A. Jabbar.Design and Modeling of Horizontal Axis Wind Turbine Rotor. Master thesis in Mechanical Engineering,Osmania University,India, (2012).

[31] J. N. Sørensen. General Momentum Theory for Horizontal Axis Wind Turbines springer, vol. 4, (2015).

[32] T. Burton, N. Jenkins, D. Sharpe, and E. Bossanyi. Wind Energy Handbook, Second Edition. John Wiley \& Sons, Ltd (2011).

[33] A. Sadikin et al. . A Comparative Study of Turbulence Models on Aerodynamics Characteristics of a NACA0012 Airfoil," Int. J. Integr. Eng., vol. 10, no. 1, (2018), pp. 134-137.

[34] B. A. Jabbar and N. Sanke. Design and Modeling of Horizontal Axis Wind Turbine Blade," Natl. Conf. Recent Adv. Mech. Eng. ,UCE, OU,Hyderabad, (2012), pp. 16-17.

[35] R. L. U. de F. Pinto and B. P. F. Gonçalves. A revised theoretical analysis of aerodynamic optimization of horizontal-axis wind turbines based on BEM theory. Renew. Energy, vol. 105, (2017), pp. 625-636.

[36] A. H. Abdullah and F. Wang. Modelling Thermal Environmental Performance In Top-lit Malaysian Atrium Using Computational Fluid Dynamics ( CFD ). International J. of Integrated Eng.., vol. 1, (2011), pp. $27-42$.

[37] A. Sadikin et al..Numerical Simulation in Transient Flow of Non-Newtonian Fluid in Nozzles during Filling Process. International Journal. of Integrated Engineering., vol. 10, no. 1, (2018), pp. 92-95.

[38] Y. El khchine and M. Sriti. Performance prediction of a horizontal axis wind turbine using BEM and CFD methods. MATEC Web Confirence, (2016).

[39] P. Saravanan, K. M. Parammasivam, and S. Selvi Rajan. Experimental investigation on small horizontal axis wind turbine rotor using winglets. J. Appl. Sci. Eng., vol. 16, no. 2, (2013), pp. 159-164.

[40] K. Sankaranarayanan, S. Krishnakumar, G. V. PaulRaj, and R. Rahul, (2013)."Wind Tunnel Experiment on a Small Horizontal Axis Wind Turbine,” Eighth Asia-Pacific Conf. Wind Eng. ,Chennai, India.

[41] R. Amano, I. Avdeev, R. Malloy, and M. Z. Shams. Power, structural and noise performance tests on different wind turbine rotor blade designs," Int. J. Sustain. Energy, vol. 32, no. 2, (2013), pp. 78-95.

[42] M. G. Khalafallah, A. M. Ahmed, and M. K. Emam.CFD study of some factors affecting performance of HAWT with swept blades," Int. J. Sustain. Energy, vol. 36, no. 5, (2015), pp. 489-501.

[43] M. Ibrahim, A. Alsultan, S. Shen, and R. S. Amano. Advances in Horizontal Axis Wind Turbine Blade Designs: Introduction of Slots and Tubercle," J. Energy Resour. Technol., vol. 137, no. 5, (2015).

[44] R. Belamadi, A. Djemili, A. Ilinca, and R. Mdouki. Aerodynamic performance analysis of slotted airfoils for application to wind turbine blades," J. Wind Eng. Ind. Aerodyn., vol. 151, (2016), pp. 79-99.

[45] M. H. Lee, Y. C. Shiah, and C. J. Bai. Experiments and numerical simulations of the rotor-blade performance for a small-scale horizontal axis wind turbine. J. Wind Eng. Ind. Aerodyn., vol. 149, (2016), pp. 17-29. 
[46] Y. Kim, A. Al-Abadi, and A. Delgado. Strategic Blade Shape Optimization for Aerodynamic Performance Improvement of Wind Turbines.ASME Turbo Expo 2016, (2016), pp. 1-10.

[47] V. M. Kumar, B. Nageswara Rao, and S. Farooq. Modeling and analysis of wind turbine blade with advanced materials by simulation. Int. J. Appl. Eng. Res., vol. 11, no. 6, (2016), pp. 4491-4499.

[48] M.Natesan, Dr.S.Jeyanthi, and U. Sivasathya. A Review on Design of Augmented Wind Turbine Blade for for Low Wind Speed Urban area. IJMET, vol. 8, no. 7, (2017), pp. 685-691.

[49] R. F. Ghajar and E. A. Badr. An Experimental Study of a Collector and Diffuser System on a Small Demonstration Wind Turbine. Int. J. Mech. Eng. Educ., vol. 36, no. 1, (2008), pp. 58-68.

[50] U. Göltenbott, Y. Ohya, S. Yoshida, and P. Jamieson. Aerodynamic interaction of diffuser augmented wind turbines in multi-rotor systems. Renew. Energy, vol. 112, (2017), pp. 25-34.

[51] M. Sanuki. Studies on biplane wind vanes, ventilator tubes. and cup anemometers (I). Meteorol. Geophys., vol. 1, no. 1, (1950), pp. 81-132.

[52] M. Sanuki. Studies on biplane wind vanes, ventilator tubes and cup anemometers (II). Meteorol. Res. Inst., vol. $1,(1950)$.

[53] M. Iwasaki. The experimental and theoretical investigations of windmills," Reports Res. Inst. Appl. Mech., vol. 2, no. 8, (1953), pp. 181-228.

[54] G.M.Lilley and W.J.Rainbird. A Preliminary report on the design and Performance of Ducted Windmills. report 102, Collage of Aeronautics Cranfield,UK, (1956).

[55] A. Kogan and A. Seginer. Final report on shroud design," Dep. Aeronaut. Eng. Tech. Rep. (1963),No. 32A.

[56] R. E. Wilson and P. B. S. Lissaman. Applied Aerodynamics of Wind Power Machines. Report. Oregon State University, (1974).

[57] M. O. L. Hansen, N. N. Sørensen, and R. G. J. Flay. Effect of Placing a Diffuser around a Wind Turbine. Wind Energy, vol. 3, no. 4, (2000), pp. 207-213.

[58] O. Igra. Research and development for shrouded wind turbines. European Wind Energy Conference (EWEC), Hamburg, Germany, (1984).

[59] M. J. Werle and W. M. Presz. Ducted Wind/Water Turbines and Propellers Revisited,Technical Notes. J. Propuls. Power, vol. 24, no. 5, (2008), pp. 1146-1150,.

[60] K. M. Foreman. Preliminary Design and Economic Investigations of Diffuser Augmented Wind Turbines (DAWT). Final Report, Res. Dep. Grumman Aerosp. Corp. Bethpage, New York, (1981).

[61] F. A. Al-Sulaiman and B. S. Yilbas.Thermoeconomic analysis of shrouded wind turbines. Energy Convers. Manag., vol. 96, (2015), pp. 599-604.

[62] F. A. Al-Sulaiman. Exergoeconomic analysis of ejector-augmented shrouded wind turbines.Energy, vol. 128, (2017), pp. 264-270.

[63] A. Kumar and Sachendra. Development in Augmented Turbine Technology. Int. J. Trend Res. Dev., vol. 4, no. 1, (2017), pp. 2394-9333.

[64] Y. Ohya, T. Karasudani, A. Sakurai, K. ichi Abe, and M. Inoue. Development of a shrouded wind turbine with a flanged diffuser," J. Wind Eng. Ind. Aerodyn., vol. 96, no. 5, (2008), pp. 524-539.

[65] B. Kosasih and A. Tondelli, "Experimental study of shrouded micro-wind turbine. Procedia Eng., vol. 49, (2012), pp. 92-98,

[66] R. A. Kishore, T. Coudron, and S. Priya. Small-scale wind energy portable turbine (SWEPT). J. Wind Eng. Ind. Aerodyn., vol. 116, (2013), pp. 21-31.

[67] C. D. Chaudhari, S. A. Waghmare, and A. Kotwal. Numerical Analysis of Venturi Ducted Horizontal Axis Wind Turbine for Efficient Power Generation. Int. J. Mech. Eng. Comput. Appl., vol. 1, no. 5,(2013), pp.90-93.

[68] M. Kardous, R. Chaker, F. Aloui, and S. Ben Nasrallah. On the dependence of an empty flanged diffuser performance on flange height: Numerical simulations and PIV visualizations. Renew. Energy, vol. 56, (2013), pp. $123-128$.

[69] A. Tourlidakis, K. Vafiadis, V. Andrianopoulos, and I. Kalogeropoulos. Aerodynamic Design and Analysis of A Flanged Diffuser Augmented Wind Turbine. ASME Turbo Expo 2013, vol. 8, (2013), pp. 1-10.

[70] R. Chaker, M. Kardous, F. Aloui, and S. Ben Nasrallah. Open angle effects on the aerodynamic performances of a flanged Diffuser Augmented Wind Turbine ( DAWT). Conférence Int. des Energies Renouvelables,(2013).

[71] Y. Ohya. Bluff body flow and vortex - its application to wind turbines. Fluid Dyn. Res., vol.46, no. 6, (2014).

[72] H. M. Elbakry, A. A. A. Attia, O. E. Abdelatif, and M. S. Zahran, "Simulation of Diffuser Augmented Wind Turbine Performance," World Congr. Sustain. Technol.., (2016).

[73] J. Huang and X. Zhang. Numerical Study of Air Flow Around Flanged Diffusers Using Actuator-Disk Model. ACTS Conference, Jeju Island, Korea. , (2017), pp. 1-5.

[74] R. Chaker, M. Kardous, M. Chouchen, F. Aloui, and S. Ben Nasrallah. Vortices' Characteristics to Explain the Flange Height Effects on the Aerodynamic Performances of a Diffuser Augmented Wind Turbine. J. Sol. Energy Eng., vol. 138, no. 6, (2016).

[75] K. Olasek, M. Karczewski, M. Lipian, P. Wiklak,K. Józ. Wind tunnel experimental investigations of a diffuser augmented wind turbine model. Int. J. Numer.Methods Heat Fluid Flow, vol.26,no.7, (2016), pp. $2033-2047$. 
[76] M. Kardous, R. Chaker, F. Aloui, and I. Abidi. Locations of vortices and their impacts on the aerodynamic performances of a diffuser and a DAWT," 3rd International Conference on Renewable Energies for Developing Countries (REDEC), (2016).

[77] A. Nasution and D. W. Purwanto. Optimized curvature interior profile for Diffuser Augmented Wind Turbine (DAWT) to increase its energy-conversion performance. 1st Conf. Clean Energy Technol. CET ,IEEE, (2011), pp. 315-320.

[78] A. C. Aranake, V. K. Lakshminarayan, and K. Duraisamy. Computational analysis of shrouded wind turbine configurations using a 3-dimensional RANS solver. Renew. Energy, vol. 75, (2015), pp. 818-832,.

[79] S. Hjort and H. Larsen. A multi-element diffuser augmented wind turbine. Energies, vol. 7, no. 5, (2014), pp. 3256-3281.

[80] A. Lotfi and M. Rad. Drag performance of divergent tubular-truncated cones: A shape optimization study. Int. J. Environ. Sci. Technol., vol. 9, no. 1, (2012), pp. 105-112.

[81] D. P. Georgiou, K. F. Milidonis, and N. G. Theodoropoulos. A CFD simulation of a ducted Wind Turbine with ejector assist. 11th Biennial Conference on Engineering Systems Design and Analysis, Nantes, France, (2012).

[82] T. S. Kannan, S. A. Mutasher, and Y. H. K. Lau. Design and flow velocity simulation of diffuser augmented wind turbine using CFD. J. Eng. Sci. Technol., vol. 8, no. 4, (2013), pp. 372-384.

[83] J. Wang, J. Piechna, and N. Müller. Computational Fluid Dynamics Investigation of a Novel Multiblade Wind Turbine in a Duct. J. Sol. Energy Eng., vol. 135, no. 1, (2013).

[84] S. Z. Roshan, S. Alimirzazadeh, and M. Rad. RANS simulations of the stepped duct effect on the performance of ducted wind turbine. J. Wind Eng. Ind. Aerodyn., vol. 145, (2015), pp. 270-279.

[85] S. H. Wang and S. H. Chen. Blade number effect for a ducted wind turbine. J. Mech. Sci. Technol., vol. 22 , no. 10, (2008), pp. 1984-1992.

[86] H. Ahmadi Asl, R. Kamali Monfared, and M. Rad. Experimental investigation of blade number and design effects for a ducted wind turbine," Renew. Energy, vol. 105, (2017), pp. 334-343.

[87] M. Kulak, M. Karczewski, K. Olasek, and K. Jóźwik. CFD analysis of Diffuser Augmented Wind Turbine model for wind tunnel investigation," IECON Proc. (Industrial Electron. Conf., (2016), pp. 5538-5543.

[88] H. Jafari, S. Hassanli, and K. C. S. Kwok. Performance analysis of a small wind turbine mounted inside a tall building. 18th Australasian Wind Engineering Society, Workshop McLaren Vale, South Australia, (2016).

[89] B. Ahmed, A. Ahmed, and A. Hussain. Modeling and Simulation of Diffuser Augmented Wind Turbine," 4th International Conference on Energy, Environment and Sustainable Development (EESD ), (2016).

[90] L. Michał, K. MacIej, M. Jakub, and J. Krzysztof, "Numerical simulation methodologies for design and development of Diffuser-Augmented Wind Turbines-analysis and comparison. Open Eng., vol. 6, no. 1, (2016), pp. 235-240,

[91] L. Michal, K. Maciej, and J. Krzysztof. Analysis and comparison of numerical methods for design and development of small Diffuser-Augmented Wind Turbine (DAWT). IECON Proc. (Industrial Electron. Conf., (2016), pp. 5525-5531.

[92] V. V. Dighe, F. Avallone, J. Tang, and G. van Bussel. Effects of Gurney Flaps on the Performance of Diffuser Augmented Wind Turbine," 35th Wind Energy Symposium, Grapevine, Texas, (2017).

[93] N. Oka, M. Furukawa, K. Kawamitsu, and K. Yamada. Optimum aerodynamic design for wind-lens turbine,” $J$. Fluid Sci. Technol., vol. 11, no. 2, (2016).

[94] K. Mansour and P. Meskinkhoda. Computational analysis of flow fields around flanged diffusers," J. Wind Eng. Ind. Aerodyn., vol. 124, (2014), pp. 109-120.

[95] B. Kosasih and H. Saleh Hudin. Influence of inflow turbulence intensity on the performance of bare and diffuseraugmented micro wind turbine model," Renew. Energy, vol. 87, (2016), pp. 154-167.

[96] S. A. H. Jafari and B. Kosasih. Flow analysis of shrouded small wind turbine with a simple frustum diffuser with computational fluid dynamics simulations," J. Wind Eng. Ind. Aerodyn, vol. 125, (2014), pp. 102-110.

[97] B. Kosasih and S. A. Jafari .High-Efficiency Shrouded Micro Wind Turbine for Urban-Built Environment,” Appl. Mech. Mater., vol. 493, (2014), pp. 294-299.

[98] M. Lipian, M. Karczewski, and K. Olasek .Sensitivity study of diffuser angle and brim height parameters for the design of 3 kW Diffuser Augmented Wind Turbine," Open Eng., vol. 5, no. 1, (2015), pp. 280-286.

[99] Y. Ohya, T. Karasudani, T. Nagai, and K. Watanabe. Wind lens technology and its application to wind and water turbine and beyond," Renew. Energy Environ. Sustain., vol. 2, (2017).

[100] T. Y. Chen, Y. T. Liao, and C. C. Cheng. Development of small wind turbines for moving vehicles: Effects of flanged diffusers on rotor performance," Exp. Therm. Fluid Sci., vol. 42, (2012), pp. 136-142.

[101] W. X. Wang et al.. Experimental investigation into the influence of the flanged diffuser on the dynamic behavior of CFRP blade of a shrouded wind turbine. Renew. Energy, vol. 78, (2015), pp. 386-397.

[102] J. F. Hu and W. X. Wang. Upgrading a shrouded wind turbine with a self-adaptive flanged diffuser. Energies, vol. 8, no. 6, (2015), pp. 5319-5337.

[103] H.Sun and Y.Kyozuka.Analysis of performances of a shrouded horizontal axis tidal turbine. (Oceans), Yeosu,South Korea, (2012). 